\title{
Isolated Effect and Sensitivity of Agricultural and Industrial Waste Ca-Based Stabilizer Materials (CSMs) in Evaluating Swell Shrink Nature of Palygorskite-Rich Clays
}

\author{
Fazal E. Jalal, ${ }^{1}$ Babak Jamhiri $\mathbb{D},{ }^{1}$ Ahsan Naseem $\left(\mathbb{D},{ }^{2}\right.$ Muhammad Hussain $\mathbb{D},{ }^{3}$ \\ Mudassir Iqbal $\mathbb{1},{ }^{1}$ and Kennedy Onyelowe $\mathbb{C}^{4}$ \\ ${ }^{1}$ Department of Civil Engineering, Shanghai Jiao Tong University, Shanghai 200240, China \\ ${ }^{2}$ Civil Engineering Department, University of Ghent, Technologiepark Zwijnaarde, Ghent, Belgium \\ ${ }^{3}$ Department of Civil Engineering, Tsinghua University, Beijing, China \\ ${ }^{4}$ Department of Civil and Mechanical Engineering, Kampala International University, Kampala, Uganda
}

Correspondence should be addressed to Kennedy Onyelowe; kennedychibuzor@kiu.ac.ug

Received 1 July 2021; Accepted 20 October 2021; Published 1 November 2021

Academic Editor: Zhuang-Zhuang Liu

Copyright (c) 2021 Fazal E. Jalal et al. This is an open access article distributed under the Creative Commons Attribution License, which permits unrestricted use, distribution, and reproduction in any medium, provided the original work is properly cited.

This paper evaluates the suitability of sugarcane bagasse ash (SCBA) and waste marble dust (WMD) on the geotechnical properties of Palygorskite-rich expansive clays located in northwest Pakistan. These problematic soils exhibit undesirable characteristics which greatly affect the pavements, boundary walls, slab-on-grade members, and other civil engineering infrastructures. A series of geotechnical tests were performed on soil specimens using prescribed percentages of the aforementioned Ca-based stabilizer materials (CSMs). The investigation includes X-Ray Diffraction (XRD) Analysis, Scanning Electron Microscopy (SEM), X-Ray Fluorescence (XRF) tests, and physicomechanical properties such as moisture-density relationship, Atterberg's limits, swell pressure, and an ANN-based sensitivity analyses of overall swell pressure development. The outcomes of these experimental investigations showed that the addition of CSMs into the expansive soils increased to 4\% SCBA and 10\% WMD, the plasticity index reduced by $30 \%$ and $49 \%$, the volumetric swell decreased from approximately $49 \%$ to $86 \%$ and $63 \%$, and the swelling pressure reduction was from $189 \mathrm{kPa}$ to $120 \mathrm{kPa}$ and $160 \mathrm{kPa}$ (about $15 \%$ and $36 \%$ ), respectively. It is interesting to note that replacement with specified CSM accelerated the strength of soil at extended curing periods and the optimum improvement in the strength behavior of the soil was also recorded. Moreover, with addition of the respective CSMs, the compactability and strength characteristics were ameliorated, while plasticity was significantly lowered. Given the amount of SCBA and WMD produced annually, their utilization for the stabilization of problematic soils, even in relatively low concentrations, could potentially have a substantial impact on the sustainable reuse of these waste materials.

\section{Introduction}

The expansive soils (also known as; swelling soils, swellshrink soils, soft soils) exhibit complex behavior due to seasonal variation and presence of strong hydrophilic clay minerals in the form of smectites (having a 2:1 structure composed of aluminosilicate layers) such as Montmorillonite (Mt), Kaolinite, Illite, and Palygorskite. Mt is regarded as the only component in highly expansive clays that is responsible for water uptake and swelling processes $[1,2]$. The swelling of these soils in lieu with modern representations is associated with the absorption of moisture by the surface of clay particles which increases the water foils thickness present between clay particles, in addition to osmotic and capillary processes taking place simultaneously [3-7]. The five main tests used for the identification of main minerals of expansive soil are X-Ray Diffraction (XRD) Analysis, Differential Thermal Analysis (DTA), Dye Adsorption, Chemical Analysis, and Scanning Electron Microscopy (SEM) [8]. The DDL theory was proposed to predict the swelling stress and is usually used to calculate the swelling pressure through quantification of the repulsive and 
attractive forces caused by physicochemical effects at the particle scale level [9-12]. The clay minerals (smectites) have large specific surface area (SSA), plate-like minerals, and very high adsorptive capacity for water. When the SSA and cation exchange capacity (CEC) are high, the swelling pressure $\left(P_{\mathrm{s}}\right)$ and free swell (FS) in expansive clay based materials are also greater [13]. The influence of pore fluid composition on clay behavior has been the subject of considerable interest in clay mineralogy. In addition, there are several visual indicators which corroborate the presence of water-sensitive expansive clays having low inherent shear strength [14]. The water uptake is mainly due to mineralogical composition of these calamitous clays which depends on the electric charge over the surface of clay mineral, CEC, and the interlayer bonding $[15,16]$. The geological conditions, engineering characteristics, and local environmental conditions also govern the expansivity of such soils. The entry of moisture in these clay minerals causes extensive damage to foundations of buildings, cracking of road pavements, upheaval and breakup of building foundations, pavements, slopes, and linings of the reservoirs as well as channels; especially the light civil engineering structures are adversely damaged [17-22]. The lightly loaded structures experience comparatively more settlement and/or heaving as a result of swell-shrink nature of the expansive soils [23]. Expansive soils are causing substantial damage to roads, buildings, and various underground utilities in the northwestern part of Pakistan, as shown in Figure 1. Their importance can further be explained by cost of resulting damages which exceed approximately 10 billion US dollars annually in the United States. The residential areas affected by the expansive soil lie over 10 million square meter land which causes an approximate damage of one billion US dollar annually in China $[24,25]$.

Today, the developmental works in society are flourishing but the environment is also deteriorating due to rapid industrialization which leads to both pollution and generation of solid wastes, thus causing hazardous conditions [26]. According to the Global Waste Generation-Statistics and Facts 2019, the global waste generation is forecasted to increase by $70 \%$ by 2050 , implying that almost 8 billion population today is responsible for production of 2.5 billion tons of waste [22]. The incorporation of waste products and fibers blended with other chemical agents ameliorates stiffness and strength properties of expansive soils [27]. Such soils are stabilized by incorporating multiple additives including traditional and nontraditional stabilizers [28] which are well documented in literature: lime $[14,29]$, cement [30-32], fly ash [33-36], rice husk ash [37-40], waste ceramic dust [41-43], nanosilica [44-48], calcium carbide residue [49-51], and so on. Furthermore, the chemical stabilization of expansive soil has been focused by number of researchers [52-56] and it was revealed that fly ash, lime, cement, and $\mathrm{CaCl}_{2}$ are useful additives and have significantly improved the engineering properties of problematic soils [57-59]. It is pertinent to mention that when sulphate rich soils are stabilized using the Ca-based stabilizer materials (CSMs), "SO 4 -induced heave" occurs due to formation of ettringite which arises from the reactive nature of sulphates in the expansive clays. Of the available CSMs, lime and cement are more commonly used additives in pavements construction and lightly loaded infrastructure. Moreover, variety of methods with specific limitations could be used to improve expansive clays, for instance, using chemical additives, prewetting, moisture control, and thermal methods $[60,61]$. In previous works, Jute and coir fiber $(0.25,0.5$, 0.75 , and $1 \%)$, bagasse ash $(3,6,9$, and $12 \%)$, burned olive waste $(0.0,2.5,5.0$, and $7.5 \%)$, palm oil fuel ash $(10,20,30$, and $40 \%)$, egg shell $(10,20,30$, and $50 \%)$, tamarind kernel powder $(2,4$, and $8 \%)$, wheat husk ash $(3,5,7,9$, and $11 \%)$, xanthan gum $(0,0.5,1.0,1.5,2.0$, and $3.0 \%)$, and rice husk ash $(2,4,6,8,10$, and $12 \%)$ have also been widely used [22].

In this research, the varying proportion of sugarcane bagasse ash (SCBA) and waste marble dust (WMD) has been employed as geomaterials for treating the expansive soils to evaluate their efficacy or otherwise in improving plasticity, compactability, swell potential, and strength characteristics. SCBA is an agricultural by-product of bagasse during power generation and its unsafe disposal poses a serious environmental problem. Pakistan is the $6^{\text {th }}$ largest producer of sugarcane producing approximately 500,000 tons of bagasse ash. When SCBA is mixed in soil, calcium hydroxide from lime or soil reacts with silica from bagasse ash, which is similar reaction as cement reacting with soil and could be explained by two processes: (1) cation exchange and flocculation reaction (short-term reaction) and (2) pozzolanic reaction which is dependent on time and temperature and wherein formation of gelatinous compounds, i.e., calcium silicate hydrates (CSH) and calcium aluminum hydrates $(\mathrm{CAH})$ takes place (long-term reaction). A simplified qualitative depiction of representative soil lime-SCBA (pozzolanic) reactions is given in the following equations [27]:

$$
\begin{aligned}
\mathrm{Ca}(\mathrm{OH})_{2} & \longrightarrow \mathrm{Ca}^{2+}+2 \mathrm{OH}^{-} \\
\mathrm{Ca}^{2+}+2 \mathrm{OH}^{-}+\mathrm{SiO}_{2} & \longrightarrow \mathrm{C}-\mathrm{S}-\mathrm{H} \\
\mathrm{Ca}^{2+}+2 \mathrm{OH}^{-}+\mathrm{Al}_{2} \mathrm{O}_{3} & \longrightarrow \mathrm{C}-\mathrm{A}-\mathrm{H}
\end{aligned}
$$

It is noteworthy to mention that SCBA is efficient in controlling the plasticity and shrink-swell potential of expansive soils owing to presence of large amount of silica and variety of other oxides which improves the pozzolanic activity [62-66]. On the other hand, WMD is largely employed for stabilization of black cotton soils (BCS) during construction of pavements. In India, Rajasthan province produces $95 \%$ of total marble from 4000 marble mines which is considered as the largest marble production across the globe. During production of marble, $70 \% \mathrm{WMD}$ is produced which affects the local ecosystems and also leads to increased alkalinity. WMD improves the unconfined compression strength (UCS) of soft soils by acting as filler agent. This industrial waste material is also deemed as an addendum to lime $(\mathrm{CaO})$ for testing its efficacy in expansive soil stabilization [67-69].

To the authors' knowledge, no study till date is present that explains the independent roles of locally produced 


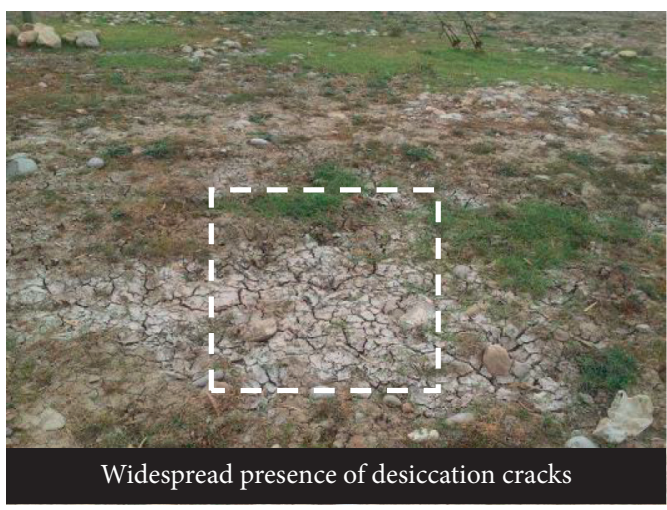

(a)

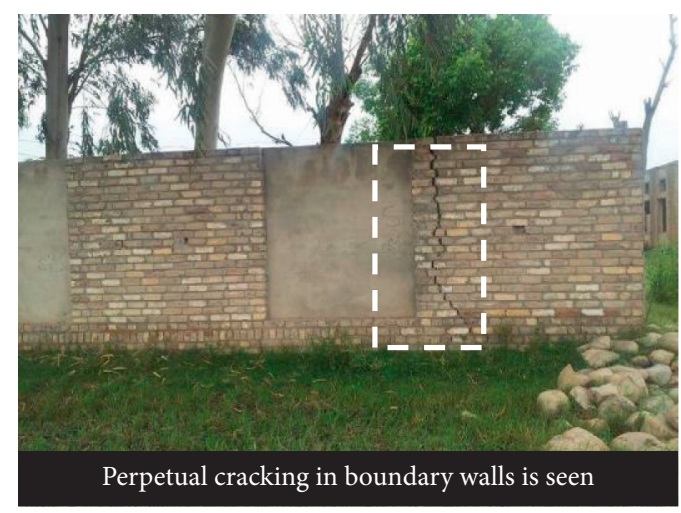

(c)

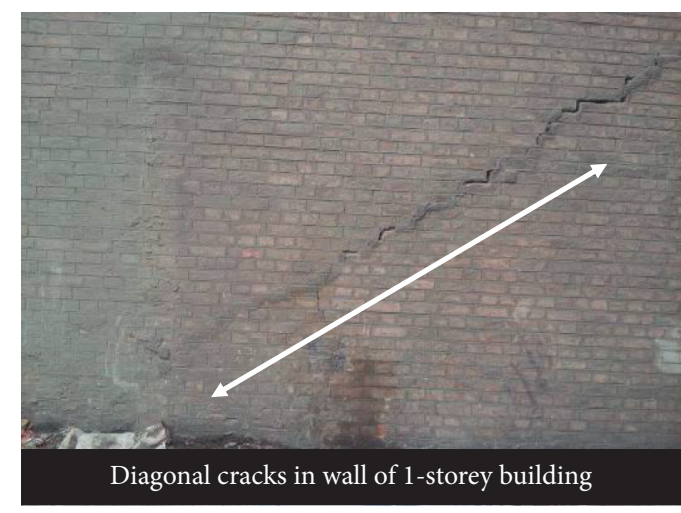

(b)

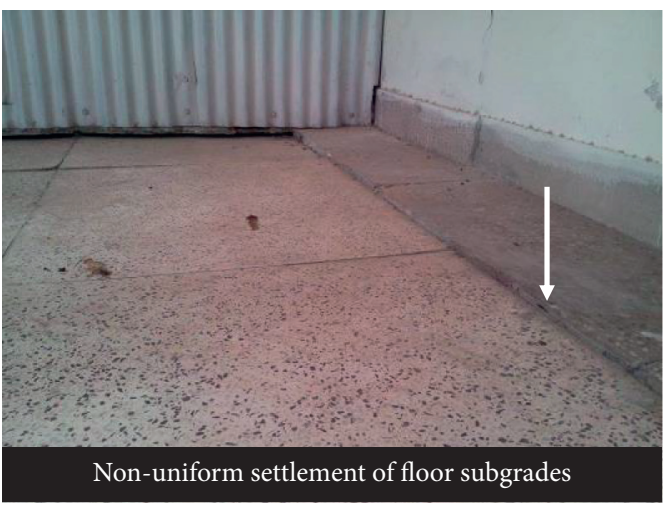

(d)

FIGURE 1: Variety of indicators of swelling clays in KPK province, north Pakistan. (a) Widespread presence of desiccation cracks. (b) Diagonal cracks in wall of 1-storey building. (c) Perpetual cracking in boundary walls. (d) Nonuniform settlement of floor subgrades.

SCBA and WMD on the geotechnical behavior of medium expansive soils, cured for 28 days, in viewpoint of microstructural tests and sensitivity analysis via Artificial Neural Network (ANN). Therefore, the objective of this study is to analyze the mechanical and morphological performance of swelling clays using SCBA/WMD as the CSMs. A detailed laboratory soil testing was performed to evaluate the index properties (consistency limits) and engineering properties (compaction, compression strength, and microstructural tests) of the soil with varying quantities $(2,4,6,8$, and $10 \%)$ of the additives and the swell pressure $\left(P_{s}\right)$ development of treated soils was analyzed in terms of interactive response of impacting factors with assistance of ANN-based sensitivity analysis. The CSMs used in this study are economically and locally available. In addition, X-ray Fluorescence (XRF) tests revealed the chemical composition of both stabilizer materials. The change in microstructural features and morphology was studied by X-Ray Diffraction (XRD) Analysis and Scanning Electron Microscopy (SEM), respectively.

\section{Significance of Research}

Expansive soils are located in various regions of Asia including China, India, Iran, Oman, Pakistan, and Saudi Arabia [29, 70-76]. The percentage land covered in countries where expansive soils are found in abundance has been illustrated in Figure 2. The engineering properties of the expansive soils have been improved in order to mitigate their volume change behavior by utilizing waste materials. As a result, the carbon footprint, energy consumption, and pollution related to waste materials disposal are significantly lessened since soil stabilization leads to decreased volume change $[77,78]$.

In the past, many researchers have attempted to stabilize the expansive soils using SCBA and WMD. Osinubi found that black cotton soil (BCS) can be stabilized by incorporating $4 \%$ to $8 \%$ SCBA at standard proctor compaction to achieve peak CBR value of $31 \%$ and increase their shear strength properties, in pavement construction [79, 80]. Kharade concluded that SCBA increased the CBR and UCS of expansive soil by $40 \%$, thereby coping with environmental concerns by reduction of sugar industry waste material, while the change is density was negligible [64, 81]. Furthermore, while investigating the effect of WMD on improvement of expansive soil properties, Jain revealed that this CSM can be utilized effectively to improve soil plasticity, increase the MDD, control the swell behavior, and increase the strength by $20 \%$ [68]. Ditta argued that the swelling pressure and FSI were plummeted (about $79.5 \%$ of untreated expansive clay soil) with use of WMD [82]. Soil with 25-30\% WMD combination is observed to be the best soil-marble dust combination foe stabilizing expansive soils [83]. Therefore, in order to study and evaluate the feasible dosage levels and seek better understanding about the SCBA and 


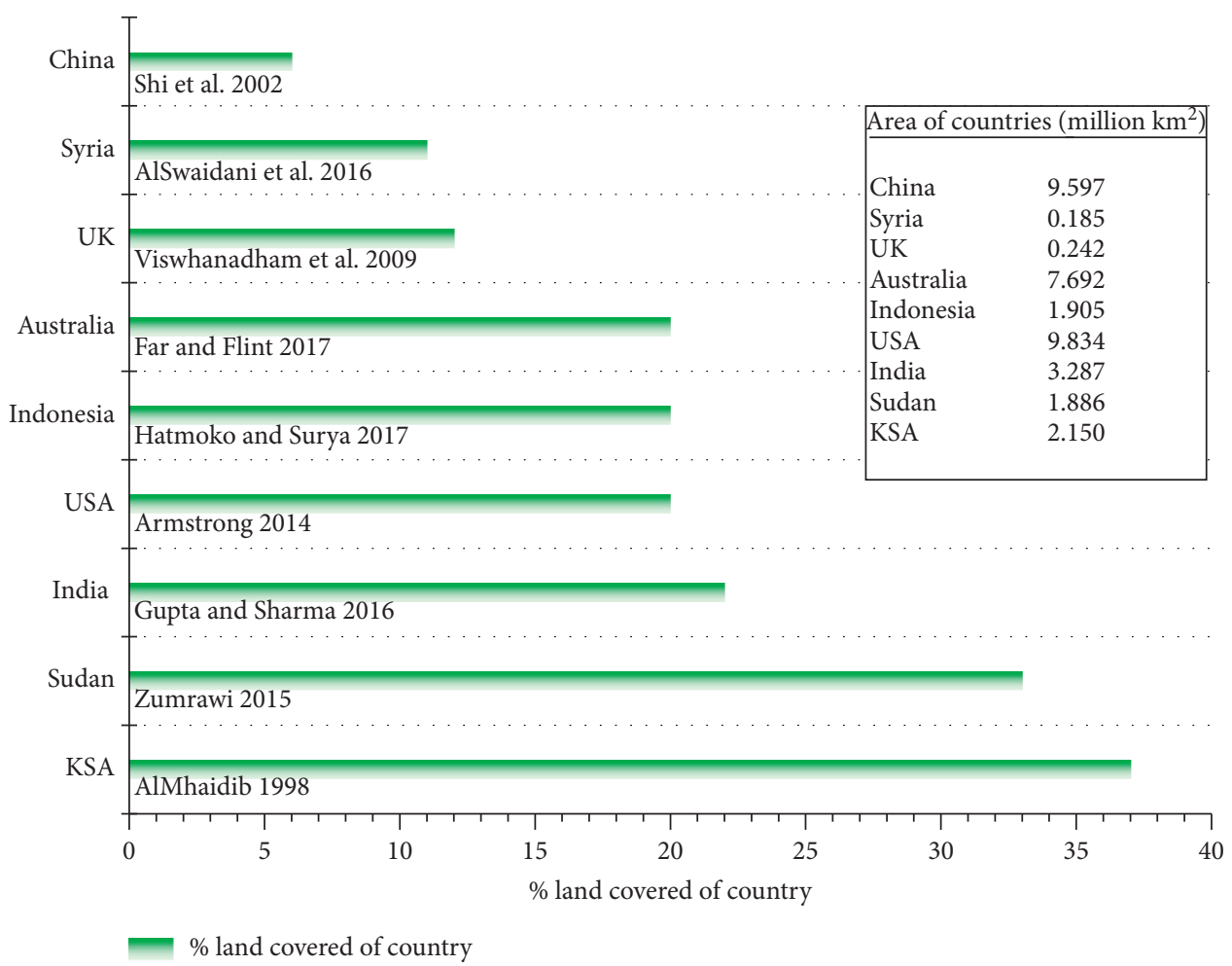

Figure 2: Percentage of covered area of expansive soils for countries where expansive soil is in abundance.

WMD stabilization, an attempt has been made to conduct a study that incorporates identical stabilizer contents for the sake of comparison in viewpoint of the already mentioned past researches.

\section{Experimental Investigation}

\subsection{Materials and Their Properties}

3.1.1. Expansive Soil. The expansive soil specimen was obtained from railway station site in Kohat city of Khyber Pakhtunkhwa (KPK) province, as shown in Figure 3, wherein the study area has been highlighted.

The Atterberg limits, grain size distribution, engineering properties, chemical characteristics, and other salient features of the expansive soil are enlisted in Table 1. According to the criteria given by Dakshanamanthy and Raman, the expansive clay is categorized as medium expansive in nature [84]. The active zone depth (AZD) of the expansive soil is the region where the effects of swelling and shrinkage are pronounced. The AZD of the soil strata was calculated $2.77 \mathrm{~m}$ which is depicted in Figure 4.

Figure 5 presents the X-Ray Diffraction (XRD) pattern of untreated expansive soil obtained by using D6 advance powder diffractometer conducted at Geoscience Advanced Laboratories, Islamabad. The soil specimen is pulverized and inserted into cavity of the glass sample holder. The specimen is slightly compressed and is flattened at microlevel in the cavity while removing the excess powder around the cavity. The sample was scanned at desired speed using Bragg's angle with the help of a graphite monochromator and $\mathrm{Cu}-\mathrm{Ka}$ radiation. JADE high score software was employed to analyze the data obtained from the diffractometer by plotting the intensities against $2 \theta$ values. The diffractometer record of the machine and the microstructural features of Palygorskite mineral have been illustrated in Figure 5. Palygorskite, chlorite, muscovite, and quartz are found as the predominant clay minerals $[68,85,86]$. In the XRD analysis, it was also revealed that diffraction grating of Palygorskite was $10.75 \mathrm{~A}^{\circ}$ and was observed as the abundant clay mineral [87]. Palygorskite (also known as attapulgite) is porous in nature, exhibits a higher adsorptive capacity, and resembles fibrous clay mineral. Figure 6 presents the Scanning Electron Microscopy (SEM) micrographs of untreated and treated Palygorskite-rich powdered expansive soil, conducted at Geoscience Advanced Laboratories, Islamabad. The target locations were chosen randomly at various magnifications by gentle beam of electromagnetic lenses, maintaining $25 \mathrm{kV}$ excitation voltages. At least three surface morphologies of each sample were captured at various magnifications $(2500 \mathrm{x}$, 5000x, and 10000x) [88]. The bigger particles in the SEM images represent presence of quartz in soil while the smaller portion of matrix illustrates presence of smectites which have higher affinity for water and are problematic.

3.1.2. Sugarcane Bagasse Ash (SCBA) and Waste Marble Dust (WMD). To evaluate the oxides composition of the CSMs, $\mathrm{X}$-ray Fluorescence (XRF) analyses were conducted and the results for SCBA and WMD have been summarized in Table 2. It is evident from an examination of the chemical composition that SCBA exhibits pozzolanic characteristics 


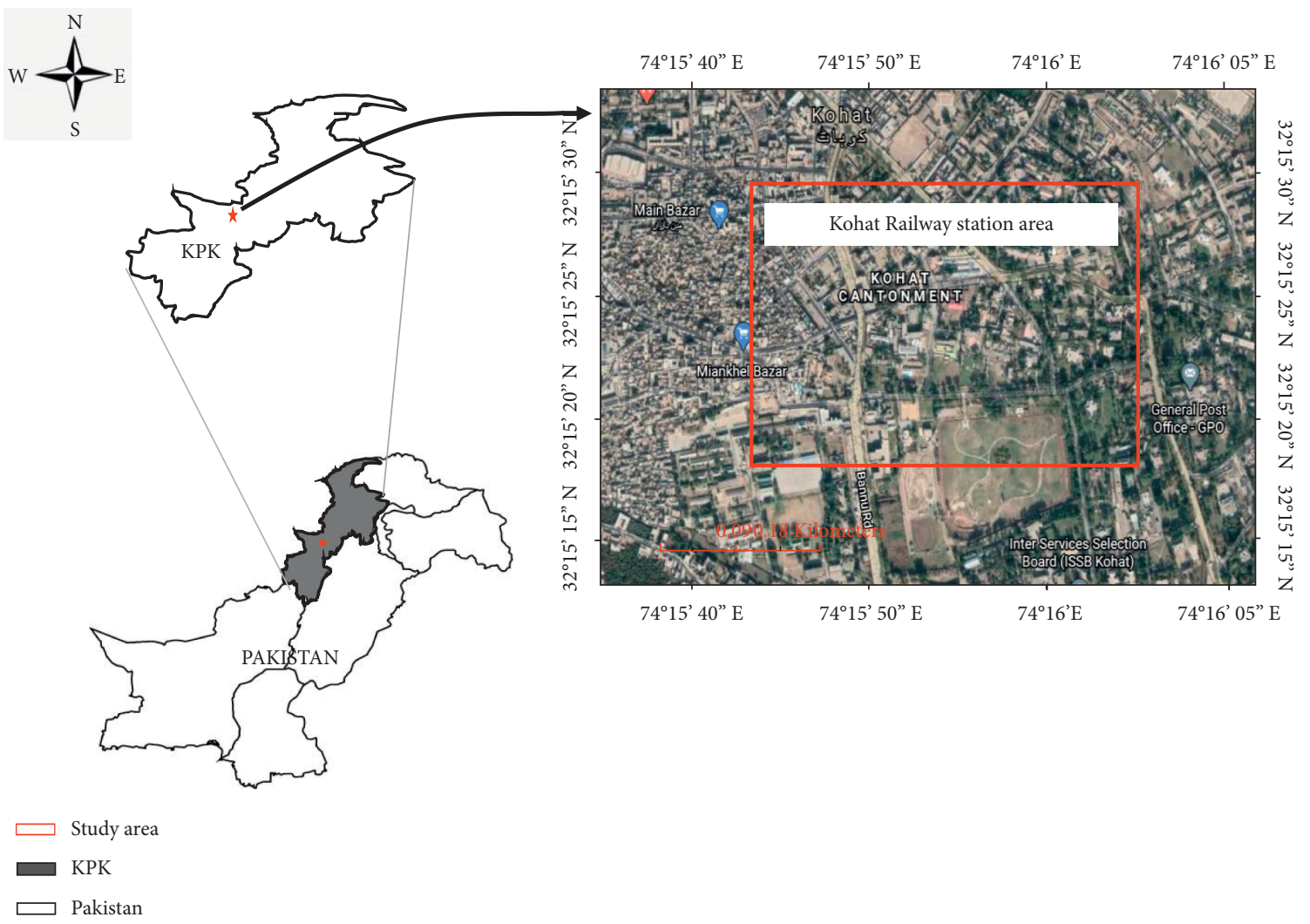

FIgURE 3: Location of study area (highlighted).

TABle 1: Physical properties of Palygorskite-rich expansive soil.

Property

Atterberg limits

Grain size distribution

Chemical characteristics

General characteristics

Normalized proctor test

Strength characteristics Sand equivalent

Liquid limit $w_{\mathrm{L}}(\%)$
Plastic limit $I_{\mathrm{p}}(\%)$

Gravel (>4.75 mm) (\%)

Sand $(0.074$ to $4.75 \mathrm{~mm})(\%)$

Clay and silt $(<0.074 \mathrm{~mm})(\%)$ Activity

Iron oxide-alumina (\%) $\mathrm{Fe}_{2} \mathrm{O}_{3}-\mathrm{Al}_{2} \mathrm{O}_{3}$

Carbonate $\mathrm{CaCO}_{3}(\%)$

Chloride $\mathrm{NaCl}(\%)$

Sulphates $\mathrm{CaSO}_{4}(\%)$

Insoluble residue I.R. (\%)

Linear shrinkage

Specific gravity, $G_{\mathrm{s}}$ $\mathrm{pH}$

Soil classification

Free swell index (FSI) (\%)

Swell pressure $(\mathrm{kPa})$

Optimum water content (\%)

Maximum dry density $\left(\mathrm{kN} / \mathrm{m}^{3}\right)$

Unconfined compression strength $(\mathrm{kPa})$

By piston test (\%)

$\begin{array}{cc}\text { ASTM D4318-00 } & 42.7 \\ \text { ASTM D4318-00 } & 21.2 \\ \text { ASTM 98 D422-63 } & 0 \\ \text { ASTM 98 D422-63 } & 3 \\ \text { ASTM 98 D422-63 } & 97 \\ \text { ASTM 98 D422-63 } & 0.57 \\ & 25.2 \\ & 22 \\ & 0.42 \\ & 0.06 \\ & 52.3 \\ \text { ASTMD 854-02 } & 5 \% \\ & 2.71 \\ \text { ASTM D2487-00 } & 7.1 \\ \text { ASTM D5890-02 } & \text { CL-OL } \\ \text { ASTM D4546 } & 195 \\ \text { ASTM D D698-07 } & 189 \\ \text { ASTM D D698-07 } & 14.9 \\ \text { ASTM D2166-00 } & 18.1 \\ & 72.21 \\ & 4.7 \\ & 3.4\end{array}$

whereas the WMD is observed to have nucleating properties $[62,67,69,92]$. These waste materials act as an environmental burden and therefore need to be safely and effectively handled.
3.2. Testing Methodology Adopted. The laboratory tests were performed in accordance with relevant standards as shown in Table 1 into the following steps: a series of Atterberg limits test, compaction characteristics, swell potential, and unconfined 


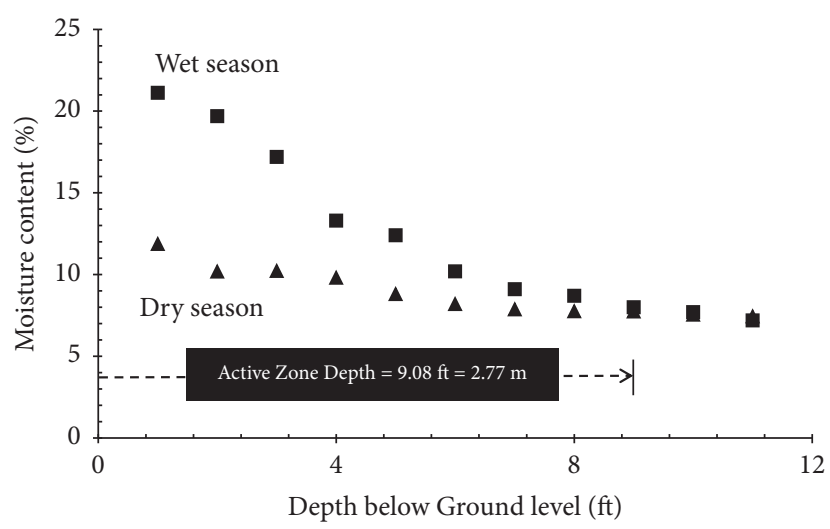

FIgURE 4: Active zone depth (AZD) of the expansive clay.

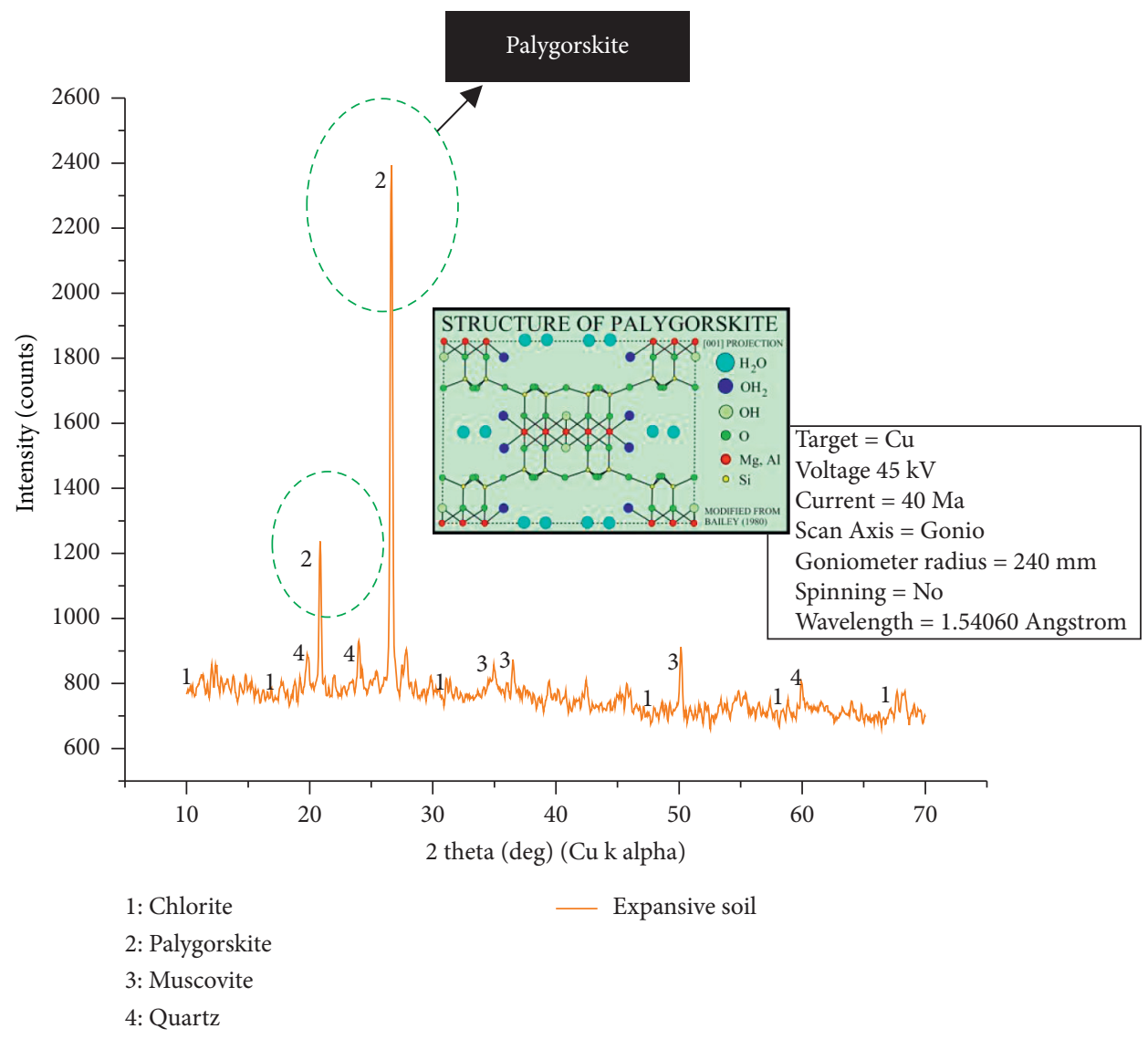

Figure 5: Diffracting peak patterns of X-rays from planes of minerals in plain expansive soil.

compression test were carried out on expansive soil mixed with various percentages of SCBA and WMD, i.e., $0 \%, 2 \%, 4 \%, 6 \%$, $8 \%$, and $10 \%$. Swelling tests were performed on specimens prepared at a moisture content similar to the OMC for untreated soil with different dry densities depending on the standard compaction. The purpose of mixing these waste materials in expansive soil was to perform a comparative study according to preset mix design by conducting microstructural tests such as XRD, XRF, and SEM. It was done to analyze the positive changes in geotechnical characteristics of expansive soil on every modification level. To grasp the existing isolated effect of each CSM, an Artificial Neural Network (ANN) based sensitivity analysis has been incorporated in order to simplify the complex response of treated soils and to analyze the variation of $P_{\mathrm{s}}$ against several parameters. To do so, four parameters were selected as dosage of agents (\%), PI, OMC, and MDD, which were used for carrying out the sensitivity-based analysis. In the ANN model, K-folded mechanism has been applied by dividing the dataset into five fractions including a model on four fractions for training and on the fifth section for validation. Accordingly, cross-validation of randomly folded datasets is performed by taking one group as hold-out or test 


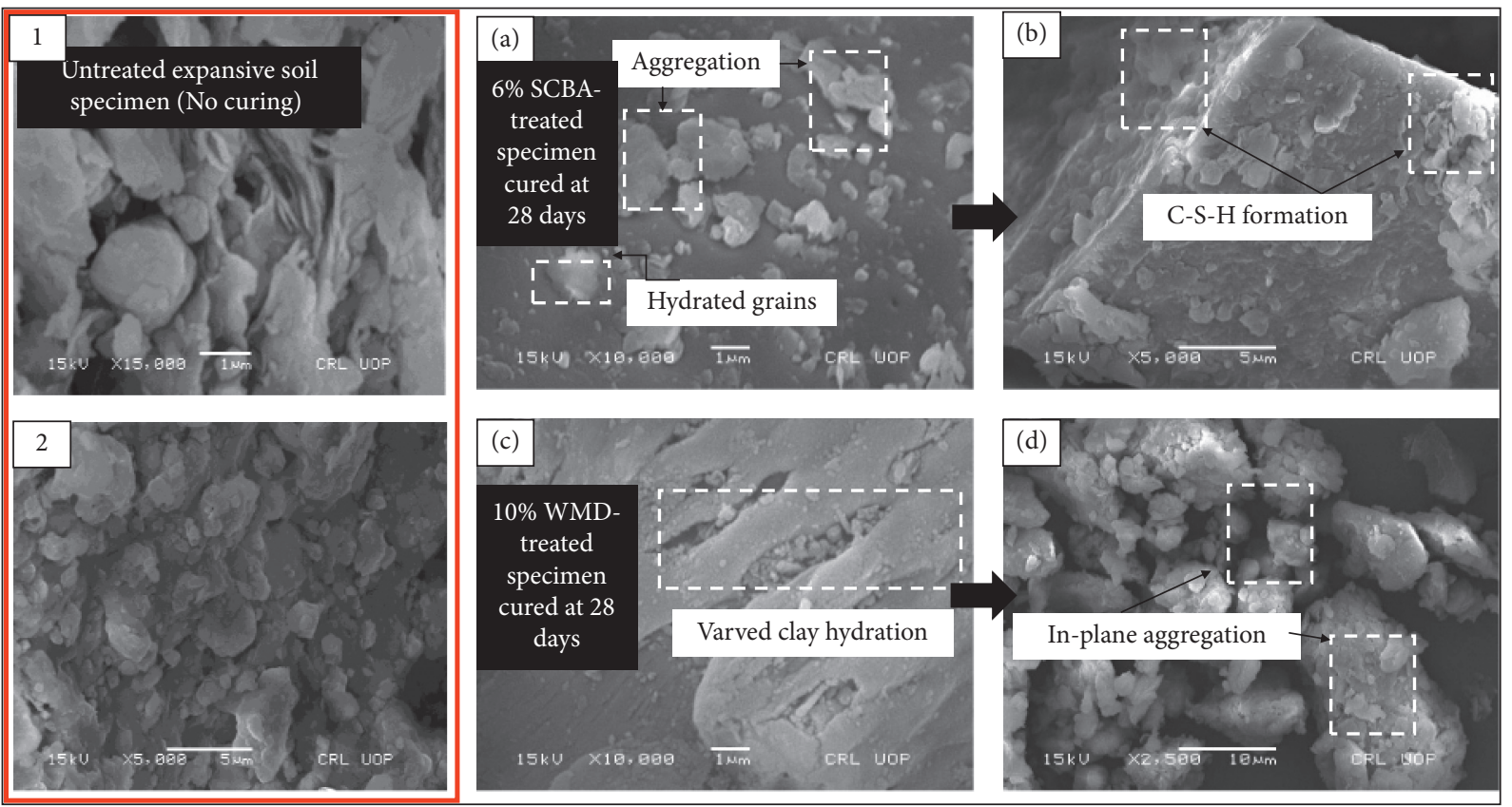

FIGURE 6: SEM in-plane micrographs for untreated and treated (6\% SCBA and 10\% WMD) expansive soil.

TAвLE 2: Oxides compositions of Ca-based soil stabilizer materials (CSMs) from the past literature versus those used in this study.

\begin{tabular}{|c|c|c|c|c|c|c|}
\hline \multirow{3}{*}{ Constituents (\%) } & \multicolumn{6}{|c|}{ Ca-based soil stabilizers } \\
\hline & \multicolumn{3}{|c|}{ Sugarcane bagasse ash, SCBA } & \multicolumn{3}{|c|}{ Waste marble dust, WMD } \\
\hline & [89] & {$[62]$} & This study & [90] & {$[91]$} & This study \\
\hline $\mathrm{SiO}_{2}$ & 71.63 & 85.50 & 47.87 & 0.54 & 4.4 & 0.95 \\
\hline $\mathrm{Al}_{2} \mathrm{O}_{3}$ & 9.37 & 1.10 & 10.02 & 0.44 & 35.9 & 0.16 \\
\hline $\mathrm{Fe}_{2} \mathrm{O}_{3}$ & 5.1 & 1.33 & 5.65 & 0.11 & 0.09 & 0.15 \\
\hline $\mathrm{CaO}$ & 5.9 & 2.88 & 11.69 & 54.65 & 54 & 53.75 \\
\hline $\mathrm{MgO}$ & 1.67 & 2.10 & 2.76 & 1.43 & 0.78 & 0.76 \\
\hline $\mathrm{K}_{2} \mathrm{O}$ & 2.5 & 2.76 & 2.59 & 0.17 & - & 0.04 \\
\hline $\mathrm{Na}_{2} \mathrm{O}$ & - & 0.96 & 2.36 & 0.05 & - & 0.64 \\
\hline $\mathrm{TiO}_{2}$ & - & 0.16 & 0.78 & - & - & 0.05 \\
\hline Others & 3.13 & 3.21 & 0.10 & - & 3.86 & 0.04 \\
\hline Loss on ignition & - & - & 16.08 & 42.36 & - & 43.40 \\
\hline
\end{tabular}

dataset and the remaining groups as training datasets. Then, data fitting is being performed on the training set and being evaluated on the test set. Iterations of these procedures and the evaluation scoring continue until the confidence of the model reaches its maximum and deviations are discarded. Finally, the precision of these method can be evaluated by Root Mean Square Error (RMSE) and Coefficient of Correlation $\left(R^{2}\right)$.

Upon completion of every curing period, the specimens were tested according to nomenclature presented in Table 3. The number shows the dosage of respective stabilizer (S: sugarcane bagasse ash; M: waste marble dust), whereas ES and UT refer to 'expansive soil' and 'untreated' specimens, respectively. The results of each SCBA/WMD mixture were compared with those of the untreated expansive soil (UT).

\section{Experimental Results}

4.1. Atterberg Limits. Figures 7(a)-7(f) show the effect of SCBA and WMD treatment on the liquid limit (LL),
TABLE 3: Sample nomenclature with expansive soil, SCBA, and WMD percentages.

\begin{tabular}{lccc}
\hline Sample code & Soil $(\%)$ & SCBA $(\%)$ & WMD $(\%)$ \\
\hline ES-UT & 100 & 0 & 0 \\
ES-2S & 98 & 2 & 0 \\
ES-4S & 96 & 4 & 0 \\
ES-6S & 92 & 6 & 0 \\
ES-8S & 90 & 8 & 0 \\
ES-10S & 88 & 10 & 0 \\
ES-2M & 98 & 0 & 2 \\
ES-4M & 96 & 0 & 4 \\
ES-6M & 92 & 0 & 6 \\
ES-8M & 90 & 0 & 8 \\
ES-10M & 88 & 0 & 10 \\
\hline
\end{tabular}

plasticity index (PI), and shrinkage limit (SL) of untreated and stabilized swelling clays, respectively. The LL of SCBA amended soil decreased by $20 \%$ while that of WMD 


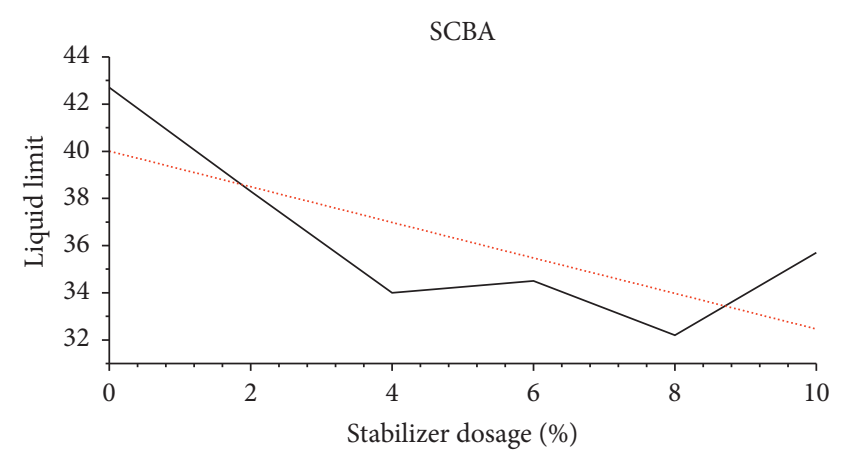

(a)

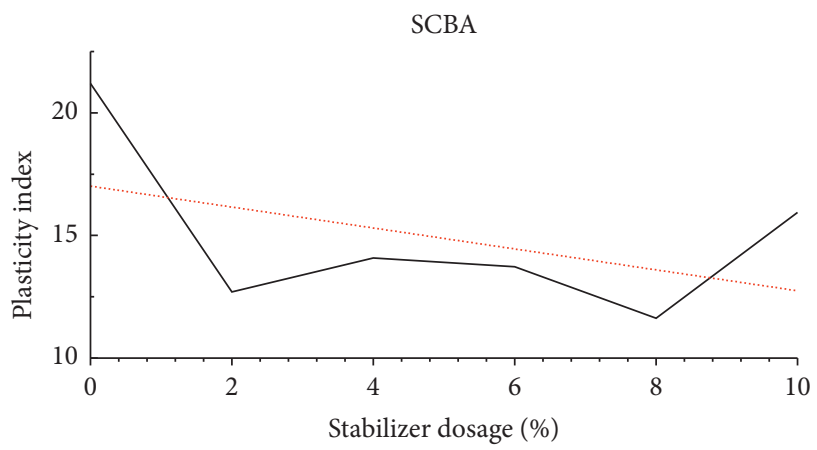

(c)

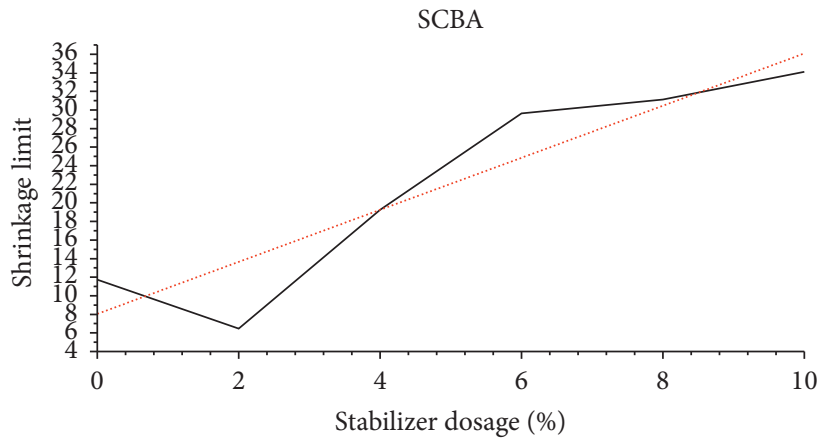

(e)

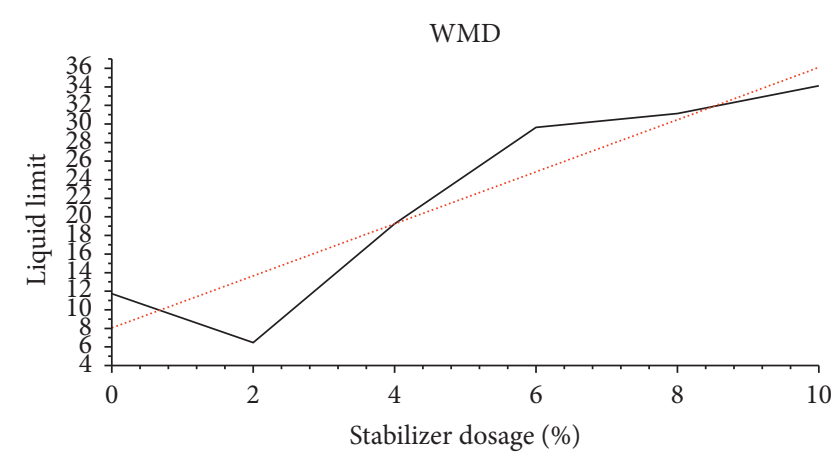

(b)

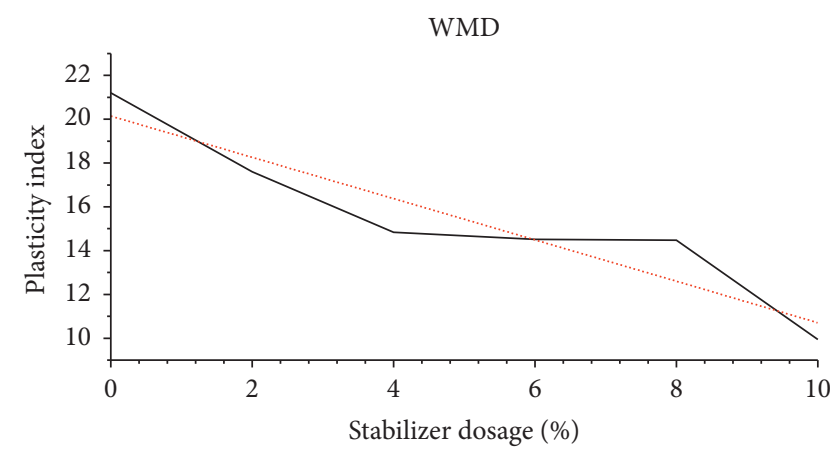

(d)

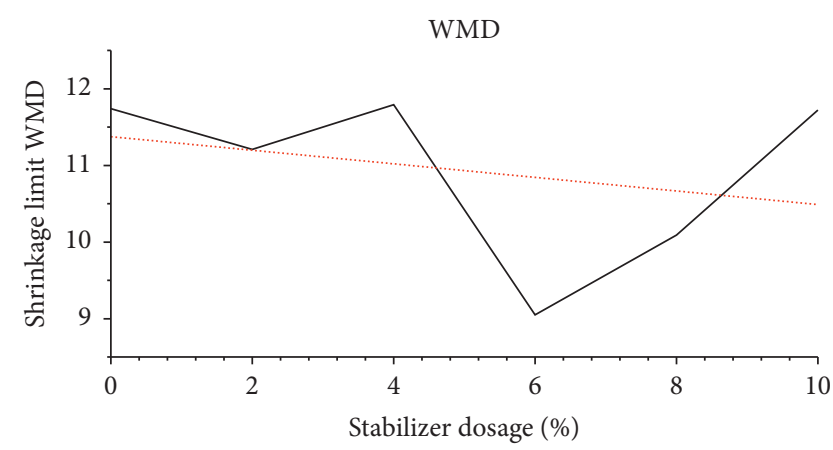

(f)

FIGURE 7: Variation of Atterberg limits by incorporating SCBA, (a) liquid limit, (c) plasticity index, (e) shrinkage limit, and by incorporating WMD, (b) liquid limit, (d) plasticity index, and (f) shrinkage limit.

amended soil decreased by $28.5 \%$ in ES-10S and ES-10M mixes, respectively. The effect of SCBA is comparatively small which may be attributed to smaller particle size, larger SSA, thereby making clay minerals more prone to attack by available calcium [20]. The simultaneous decrease in PI is due to significant reduction in LL and gentle lowering of plastic limit (PL) as indicated in Figures $7(\mathrm{~b})$ and $7(\mathrm{c})$, respectively $[21,30,93]$. In case of WMD treatment, the LL decreases significantly, so the overall PI values plummet accordingly. It is due cation exchange which causes flocculation and subsequently reduces the double layer thickness around clay particles [61]. These results of decreasing trends are consistent with findings of past researchers [91, 94, 95]. It is noteworthy to mention here that the effect of addition of $2-4 \% \mathrm{CaO}$ brings about an insignificant change in the PI value [96]. The SL also indicates an increasing trend for SCBA $\left(R^{2}=85 \%\right)$ while the WMD amended soil follows a decreasing trend, as shown in Figures 7(e) and 7(f), respectively. This is explained by coating of clay particles by WMD particles, thereby flocculating the particles. Clay matrix is filled up whereas voids and amount of water are reduced that renders the clayey soil as workable [23]. In general, ES-4S, ES-6S, ES-8M, and ES-M10 illustrate the optimum amount to yield minimum PI values. This reduction in PI is indicator of expansive soil improvement $[29,93,97]$. The result is consistent with other researchers who have utilized similar additives for modifying geotechnical properties of high plastic clays [23, 59, 68, 98].

4.2. Compaction Characteristics. Figure 8 shows the effect of SCBA and WMD addition on the compaction characteristics of untreated and treated expansive soil. It can be observed that the maximum dry density (MDD) reaches its peak for 


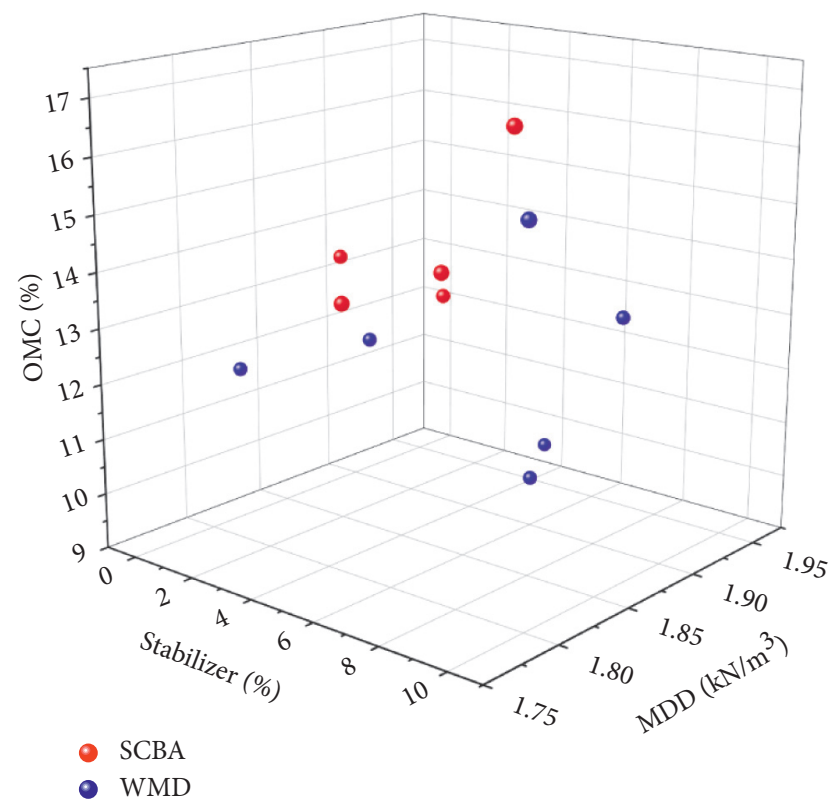

FIGURE 8: Variation of compaction characteristics (MDD and OMC) by incorporating SCBA and WMD.

ES-4S which is associated with higher density of SCBA in contrast to the expansive soil. On the other hand, in case of WMD treated soil, the MDD increases up to addition of $4 \%$ content and then lowers down with further addition of the industrial CSM, thus substantiating similar findings of [23, 47, 75, 91]. Exceeding the dosage from optimum amounts increases the OMC (up to addition of $10 \%$ stabilizer material) which could be associated with presence of additional water particles held in soil structure and higher water absorption by SCBA and WMD. The cause of reduction in MDD at higher dosage levels is probably due to particle size and $G_{\mathrm{s}}$ of expansive soil as well as the stabilizer materials. This increase in MDD corresponds to improvement of expansive soil. The decrease in MDD for ES-4S is in line previous studies which reported that, with the increase of SCBA content blended with $\mathrm{CaO}$, the MDD of the mixture slightly decreased [64, 70, 99].

The net increase in OMC until ES-10S is due to reaction taking place between clay minerals and the $\mathrm{CaO}$ content. Also, it is desirable to continue the cation exchange reaction since more water would be required for mobilizing $\mathrm{Ca}^{+2}$. Upon blending of $8 \%$ and $10 \%$ lime separately, i.e., having higher $\mathrm{CaO}$ content (which resembles the WMD in present study), in Kashmore expansive clay, the OMC increased from $14.75 \%$ value of untreated expansive soil to $16.5 \%$ and $18 \%$, respectively, while the MDD decreased from $1.89 \mathrm{kN} /$ $\mathrm{m}^{3}$ to 1.78 and $1.66 \mathrm{kN} / \mathrm{m}^{3}$, respectively. The higher value is due to increased compaction energy from the modified proctor test [96].

4.3. Swell Potential. Figure 9 shows the swell potential results which indicate that the volumetric free swell $\left(\mathrm{FS}_{\mathrm{vol}}\right)$ of Palygorskite-rich medium expansive soil is $75 \%$. For ES-4S and ES-2M, the $\mathrm{FS}_{\mathrm{vol}}$ value is dropped reaching about $3 / 4^{\text {th }}$ of the untreated soil. Furthermore, for ES-6S, the FS $_{\mathrm{vol}}$ of this soil lowers down to $7 \%$ whereas for ES-10M the $\mathrm{FS}_{\mathrm{vol}}$ value decreases to $5 \%$. Hasan et al. [27] revealed that upon addition of SCBA up to $18.75 \%$ the linear shrinkage and free swell ratio lowered down approximately by $35 \%$ and $65 \%$, respectively, in contrast to the control expansive soil comprising Kaolinite and bentonite. The authors in [91] found that addition of $20 \%$ marble powder helped in attaining the lowest primary swell percentage of $0.35 \%$. The results are in line with the findings obtained from Atterberg's limits in Figure 7 . The recommended optimum percentage of lime is $6-10 \%$ (by weight) which effectively reduces the shrinkage of weak expansive soils. The addition of $6 \%$ lime reduces $\mathrm{FS}_{\mathrm{vol}}$ and $P_{\mathrm{s}}$ to almost zero value $[17,60,100]$. The authors in [90] found that, by incorporating WMD in conjunction with locally available river sand, $88 \%$ reduction in the $P_{\mathrm{s}}$ was observed. With further addition of both WMD and SCBA, an increase in the $\mathrm{FS}_{\mathrm{vol}}$ values is obtained. This is explained by the high percentages of stabilizer materials addition into the soil. The medium expansive soil is less susceptible to lime attack and therefore it acts as fine material when dosage of stabilizer exceeds the optimum and ultimately causes soil to swell. It is also because of increase in permeability of soil due to which moisture is uniformly distributed on compacted soil and reduced unit weight of stabilizer material compared to the Palygorskite-rich expansive soil, which increase the $\mathrm{FS}_{\mathrm{vol}}$. At low percentages of soil stabilizer materials, a higher increase was recorded in swell potential $[20,35]$. The specific gravity of WMD is less than that of SCBA; therefore the volume of WMD added is higher and WMD-soil mixture workability lowers down at decreased stabilizer content compared to workability of SCBA-soil mixture $[18,36]$. The comparison of the CSMs dosage on the FS and $P_{\mathrm{s}}$ with previous researchers work is presented in Figures 9(c) and 9(d), respectively. It could be seen that both FS and $P_{\mathrm{s}}$ follow similar trends in case of SCBA $\sim$ cement and WMD $\sim$ lime while being added at uniform dosage intervals. However, the $P_{\mathrm{s}}$ values are comparatively lower than those for cement and lime which is attributed to medium expansivity of the Palygorskite-rich expansive soil. The resemblance of SCBA with cement is due to presence of high amount of silica while the WMD and lime appear to yield similar results due to rich amount of $\mathrm{CaO}$, which is also evidenced from Table 2 .

Indications made by experimental results highlight the importance of variation of plasticity along with compaction characteristics of treated soils with various amounts of the CSMs. Interactive response of these factors on final $P_{\mathrm{s}}$ requires a thorough analysis which includes correlation among variables and counteractive sensitivity of one parameter to the entire group of parameters. The ANN model shown in Figure 10 consists of four variables, 20 nodes with one hidden layer, and one independent variable selected as the $P_{\mathrm{s}}$. As $P_{\mathrm{s}}$ is determined as the projecting factor in adopting stabilization plans for expansive soils, the relationship among the four independent variables, i.e., MDD, OMC, PI, and Dosage, has been analyzed to ascertain the importance and combined impact of these variables on developed $P_{\mathrm{s}}$ upon treatment. In the ANN model, as mentioned earlier, 


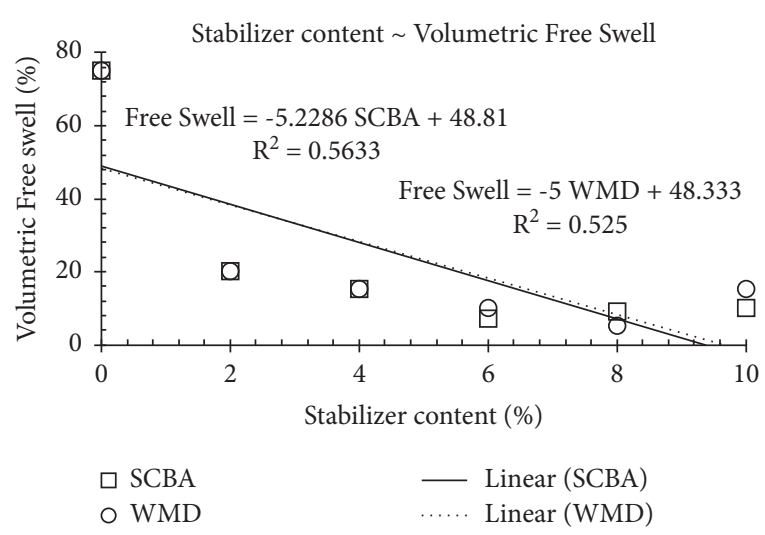

(a)

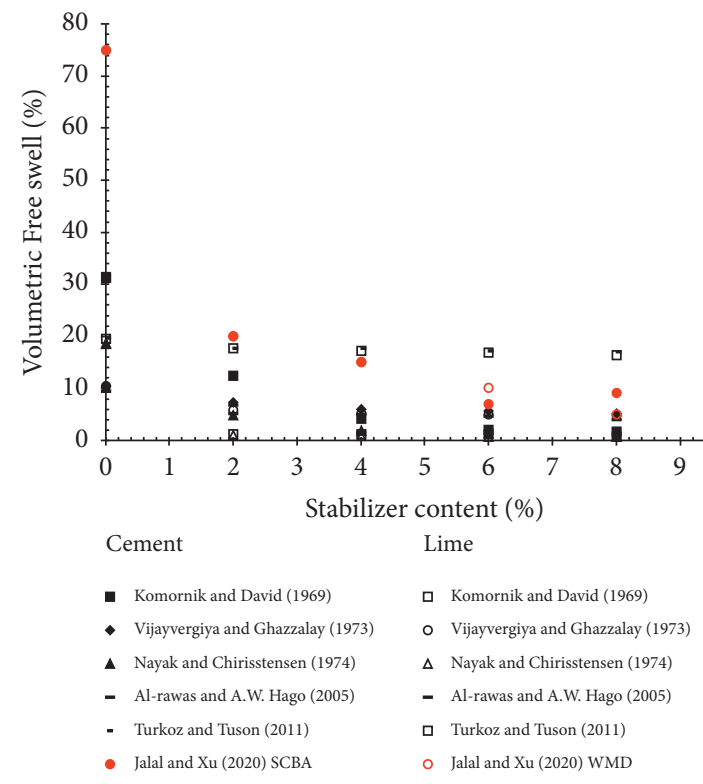

(c)

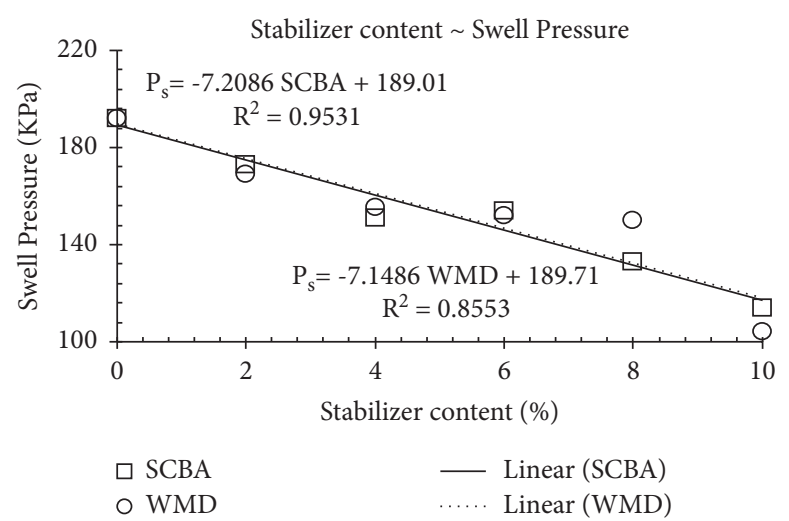

(b)

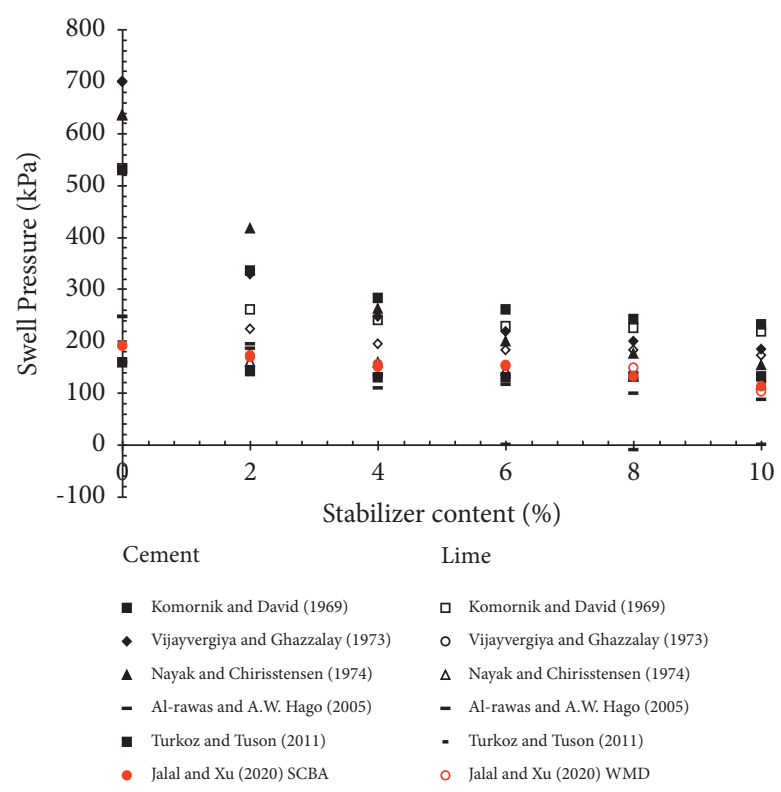

(d)

FIGURE 9: Comparison of swell potential results with previous results (volumetric free swell and swell pressure) upon addition of SCBA and WMD.

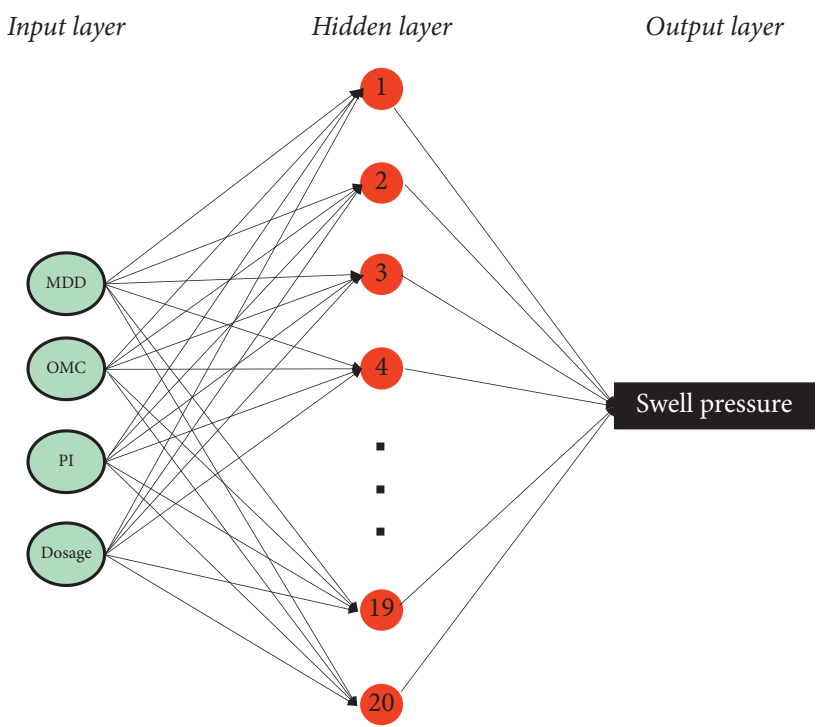

Figure 10: Artificial Neural Network (ANN) model configuration. 
K-folded mechanism has been applied by dividing the dataset into five fractions including a model on four fractions for training and on the fifth section for validation. The strength of the developed model was tested by achieving the lowest RMSE after training to determine the accuracy of the forecast of the system and 0.99 coefficient of determination was achieved in validation stage as well.

The results of ANN-based sensitivity analyses including variable importance and variable's combined impact are depicted in Figure 11. Variable importance and variable's combined impact on the overall $P_{\mathrm{s}}$ can be categorized in main and total effect, as can be seen in Figures 11(a) and 11(b), respectively. The impact of the main effect of response variable, namely, swelling pressure $(y)$, among predicting variables $\mathrm{MDD}, \mathrm{OMC}, \mathrm{PI}$, and dosage $\left(X_{i}\right.$ to $\left.j\right)$ on the predicted $P_{s}$, can be described by $\operatorname{Var}\left(E\left(y \mid x_{j}\right)\right)$ [101]. The expectation is taken with respect to the conditional distribution of $x_{1}, x_{2}, \ldots, x_{n}$ given $x_{j}$, and the variance is taken over the distribution of $x_{j}$. In other words, $\operatorname{Var}(E(y)$ $\left.x_{i}\right)$ ) measures the variation, over the distribution of $x_{i}$, in the mean of $y$ when $x_{i}$ is fixed. The affecting indices utilized are main and total effect. Main effect is the ratio of $\operatorname{Var}\left(E\left(y \mid x_{i}\right)\right) /$ $\operatorname{Var}(y)$ which gives a measure of the sensitivity of independent variable to the selected factor $x_{i}$ that reflects the relative contribution of that factor alone, not in combination with other factors. However, the total effect represents the total contribution to the variance of independent variable from all terms that involve $x_{j}$ which reflects the relative contribution of that factor both alone and in combination with other factors.

With total effect value, it is possible to represent the effects of single variables, pairs of variables, and so on. The total effect importance index for MDD, OMC, PI, and dosage is an estimate of predicted $P_{\mathrm{s}}$ as follows:

$$
\text { total effect }=\frac{\operatorname{Var}\left(E\left(y \mid x_{i}\right)\right)+\operatorname{Var}\left(E\left(y \mid x_{1}, \ldots, x_{j}\right)\right)}{\operatorname{Var}(y)},
$$

where $E(y)$ is the expected value of $P_{\mathrm{s}}$ and $\operatorname{Var}(y)$ is the variance of $P_{\mathrm{s}}$ with respect to the joint distribution of MDD, OMC, PI, and dosage. Moreover, profiling the combined effect is an approach for visualizing the final response by predicting what would happen if a change follows in one or two factors and finding the most important factors to optimize the desired responses. In Figures 11(c) and 11(d) of combined impact of variables, vertical red lines correspond to the current value of each factor shown in red below the horizontal axis. The red value on the vertical axis is the predicted response based on the current values of the factors.

The goal is to find the optimal combination of the four factors in the development of a certain $P_{s}$. With the aid provided in Figures 11(c) and 11(d), it is possible to judge which factor or a pair of factors can adjust the desired output. Consequently, as can be seen in Figure 11(a) for treated soils with WMD, the PI value has the most effect on other variables followed not even close by dosage. This result shows that WMD treated samples are heavily dependent on the developed PI during soil chemical reactions verifying the previous observations and suggesting that considerable reduction of PI is expected when treating soil with WMD agents and leading to a comparatively more increase in UCS against SCBA treated samples.

The behavior of SCBA treated samples is prevalent in chemical stabilization since the effect of dosage on the final $P_{\mathrm{s}}$ has the governing dominance. Although SCBA treated samples showed the most sensitivity towards the dosage, they also react to the variation of compaction characteristics, namely, OMC, which is almost negligible for WMD treated samples. But, for WMD treated samples, the effect of change in PI on the $P_{\mathrm{s}}$ is more concerning. As it can be seen in Figure 11(c), ES-6M has smaller variation in $P_{\mathrm{s}}$ ranging from 120 to $180 \mathrm{kPa}$ while samples with similar amount of dosage but with SCBA have larger variation ranging from 110 to $200 \mathrm{kPa}$. Higher range of $P_{\mathrm{s}}$ in treated samples with SCBA indicates that adoption of any amount of stabilizer would result in higher variation in expansion threshold which in turn requires a meticulous design and practice.

However, the practical consistency of treated samples is not depending on a sole factor such as dosage; for example, WMD treated samples wherein PI of treated soils upon treatment will determine the course of expansion. For WMD treated samples, due to lower specific gravity and consequent workability compared to SCBA treated samples, any change in PI due to variation of compaction characteristics and dosage incorporation in practice will affect the course of pozzolanic reactions and final UCS needed for design. That is why variation of PI in treated samples with WMD has the most controlling effect among other parameters as shown in Figure 11(c) adding to the overall sensitivity of WMD treated samples to reduction of PI upon treatment.

4.4. Unconfined Compression Strength. Figure 12 shows the unconfined compression strength (UCS) of untreated and treated specimens using aforementioned CSMs at prescribed percentages over interval of 3, 7, 14, and 28 days. At 3-day curing, the UCS of SCBA and WMD amended soil increased by $36 \%$ and $255 \%$ (306.40 $\mathrm{kPa}$ for WMD treated soil) for ES$10 \mathrm{~S}$ and ES-10M, respectively. Up to 7-day curing, the UCS increased by $42 \%$ until ES-6S and ES-6M; however, the WMD treated soil suddenly increased to $343.6 \mathrm{kPa}$ while the UCS of SCBA treated soil plummeted to $130.40 \mathrm{kPa}$ for ES$10 \mathrm{~S}$ and ES-10M. It is probably due to soil lime reaction that an increase of $255 \%$ and $145 \%$ in the UCS is recorded at 3 days and 7 days, respectively. It is further explained by the formation of gelatinous cementing material with $\mathrm{CaO}$, filling the voids, thus gaining strength. The UCS of WMD treated soil witnessed a uniform increase of $98 \%$ after 14-day curing period. The UCS increased from $86.4 \mathrm{kPa}$ at 3-day curing to $282.2 \mathrm{kPa}$ at 28 days for untreated expansive soil specimen which is almost $227 \%$ increase in the compression strength. At 28-day curing period, the maximum UCS obtained for ES-4S is $346 \mathrm{kPa}$ and decreased to $289.2 \mathrm{kPa}$ for ES-6S, ES8 S, and ES-10S, whereas WMD treated soil witnessed a mild increase of $38 \%$ in the UCS. In recent research, it was revealed that UCS for ES-10M was recorded to be $630 \mathrm{kPa}$ after curing for 28 days in contrast to $525 \mathrm{kPa}$ when cured for 7 days [68]. The type of failure in case of undisturbed 


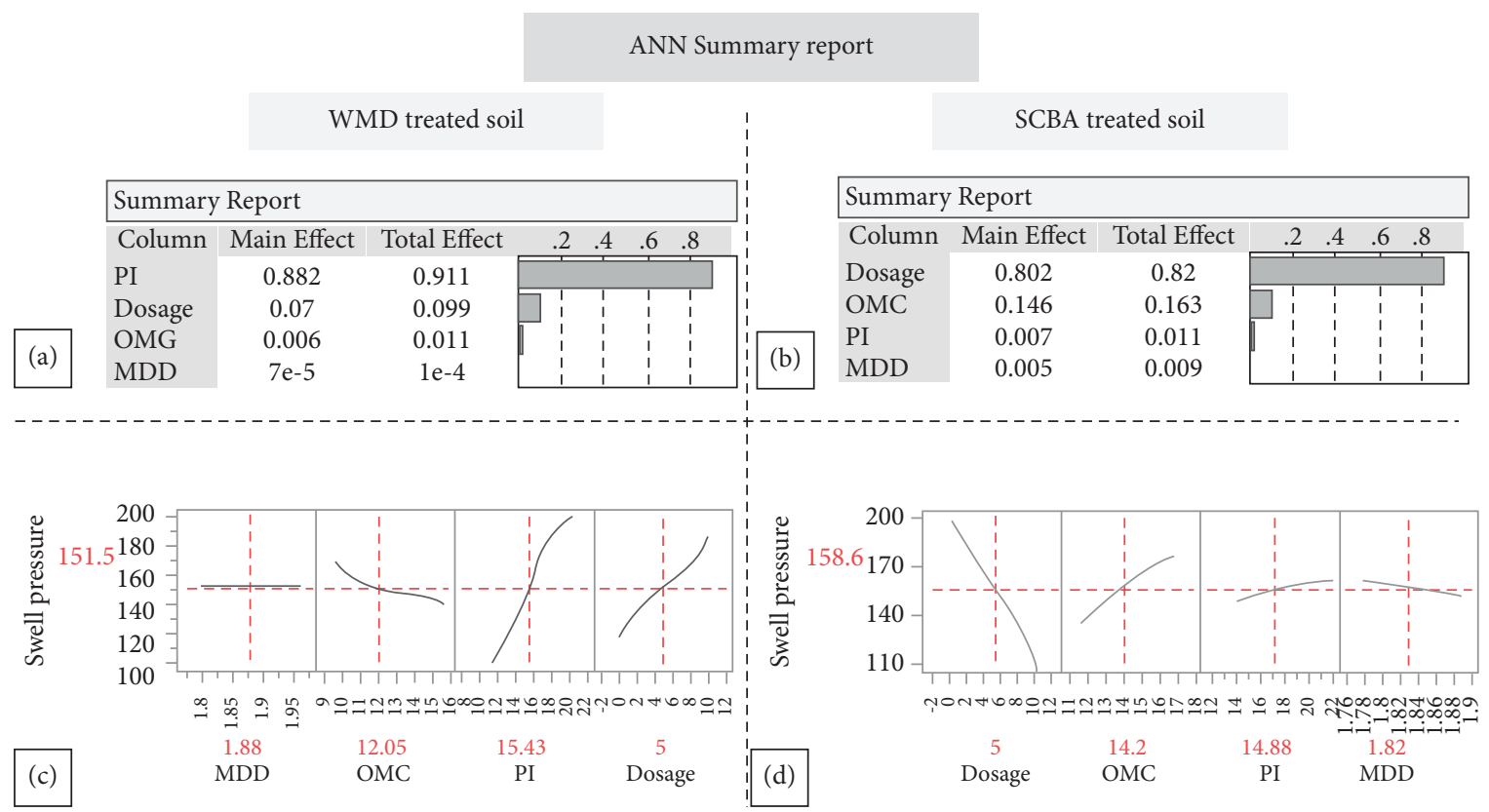

FIGURE 11: ANN-based sensitivity analyses of variable importance $(a, b)$ and variable combined impact (c, d), for WMD-treated samples and SCBA-treated samples, respectively.

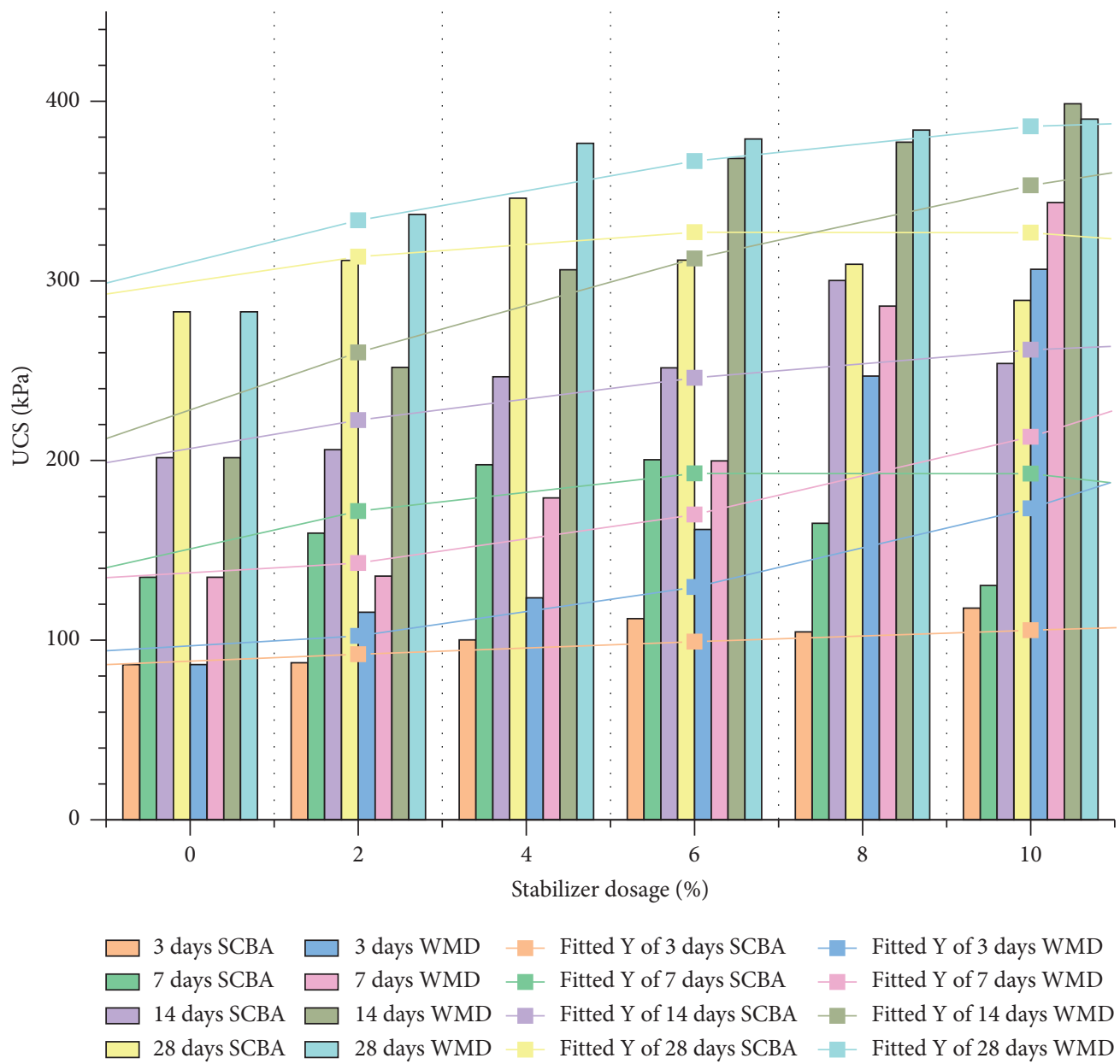

FIGURE 12: Effect on unconfined compression strength at various curing ages after addition of stabilizers. 
TABLe 4: Modified characteristics of Palygorskite-rich swelling soil (4\% SCBA+10\% WMD).

\begin{tabular}{lccccccc}
\hline Geotechnical property & LL $(\%)$ & PL (\%) & PI (\%) & MDD $\left(\mathrm{kN} / \mathrm{m}^{3}\right)$ & OMC (\%) & Volumetric swell (\%) & Swell pressure (kPa) \\
\hline Untreated soil & 42.7 & 21.2 & 21.5 & 1.81 & 14.9 & 48.81 & 189.01 \\
$4 \%$ SCBA & 36 & 21 & 15 & 1.88 & 14 & 7 & 160 \\
$10 \%$ WMD & 30 & 19.1 & 10.9 & 1.815 & 17 & 18 & 120 \\
\hline
\end{tabular}

specimen was ductile in nature, whereas compacted soil samples were recorded to have brittle failure making 60 degrees with the horizontal axis. When lime is added to soil, a hydration process is initiated and cation exchange takes place leading to flocculation of larger soil lumps. And the pozzolanic reaction products, i.e., $\mathrm{CSH}$ and $\mathrm{CH}$, are formed which govern the long-term strength of soils [20]. This clearly indicates that UCS increase is more predominant at shorter curing periods. Comparatively, WMD is found to be efficacious additive for enhancing the unconfined compressive strength of tested soils. The optimum WMD content can be observed in case of ES-10M. The addition of WMD increases the soil alkalinity alongside an increase in the specific gravity which is responsible for lower PI due to aggregation of particles at microlevel. The MDD is also increased due to lesser voids and this continuously increases the soil strength until ES-10M. However, the optimum WMD may vary depending on the native soil properties [68]. It was revealed that $10 \%$ marble powder by dry weight yielded least the swell-shrink potential and controlled compression index while having maximum unconfined compressive strength [91]. In contrast with SCBA-soil mixtures, the maximum increase in strength at 7 days is observed to be $46 \%$ for ES-6S. The increase in unconfined strength, i.e., effectiveness of SCBA at 14 and 28 days, is insignificant. This slight increase is due to lack of cementitious properties in SCBA as presented in Table 2 [93]. The results obtained are in line when pyroclastic dust is used for modifying expansive soil [23]. Considering the findings, it is also observed that, for ES-4S and ES-6S, maximum values of UCS are recorded for 3, 7, 14, and 28 days, respectively, as shown in Figure 12. Based on available literature, the increase $(10-12 \%)$ in UCS is attributed to the hydration and pozzolanic reaction between clay, SCBA, and calcium oxide content in the soil which leads to formation of CSH and $\mathrm{CAH}$; therefore it fills the void space and increases the cohesion and shear strength of the mass $[64,102]$.

It is notable that the SEM images did not show fiber-like, fine-threaded structure or cardboard (i.e., paper-like) appearance, shown in Figure 6. This is attributed to destruction of sample's structure when remolded as only the core samples exhibit the paper-like appearance. However, the Kaolinite-like structure has been notably observed at different magnifications which confirms the presence of smectite minerals in the soil sample, though the expansivity of such minerals is low in nature $[60,77,84]$. From Figures 6(a) and 6(b), the hydrated grains undergo aggregation and $\mathrm{CSH}$ formation takes place which accounts for the strength increase.

On the contrary, Figures 6(c) and 6(d) reveal that the initial varved clay hydration led to in-plane aggregation and thus formation of gelatinous $\mathrm{CSH}$ and $\mathrm{CAH}$ which is responsible for the significant increase of UCS in WMD treated soils at 28-day curing period. Relatively speaking, a compacted soil matrix is observed with an increase in curing periods of 28 days. It is due to the modification in the pore size distribution by the reaction of the WMD and expansive soil particles, the increase in cementing agents, and the aggregation of particles. The ameliorated properties of the Palygorskite-rich expansive soils treated with CSMs are listed in Table 4.

\section{Summary and Conclusions}

This paper evaluated the effect of sugarcane bagasse ash (SCBA) and waste marble dust (WMD) on the swelling potential of Palygorskite-rich medium expansive soil. The conclusions drawn from this research study on the basis of overall results can be summarized as follows:

(i) The incorporation of industrial and agriculturally based calcium stabilizer materials, namely, SCBA and $\mathrm{WMD}$, respectively, reduces the plasticity characteristics and arrests the swelling of expansive soils. WMD treated soils show considerable reduction. The extent of diagonal cracking of walls, pronounced desiccation cracks, upheaving, and/or cracking of floors and sidewalks indicated the presence of expansive soils in the region with a depth of zone of seasonal moisture variation as 2.77 meters.

(ii) The MDD of expansive soils is significantly increased with addition of WMD content up to $4 \%$ whereas the increase in MDD of SCBA treated soil is comparatively lesser reaching its peak value upon $5 \%$ addition of SCBA. Based on the results of compaction tests, the addition of $4 \% \mathrm{WMD}$, the MDD is observed to have increased by $7.6 \%$ as compared for untreated soil. The optimum percentage of SCBA is $5 \%$ which brought an increase of $3.3 \%$ in MDD of the untreated soil.

(iii) The ANN-based sensitivity analyses results indicated that PI in treated samples with WMD has the governing rule and any variation in PI will lead to a higher change in subsequent swelling pressure. On the other hand, SCBA treated samples were governed mainly by incorporated dosage and in a comparatively smaller range of variation of swelling pressure. Furthermore, it was shown that the sensitivity of WMD treated samples to a sole factor or the consequent isolated effect after treatment is more noticeable.

(iv) For soil treated with WMD, the unconfined compressive strength (UCS) increased with the passage 
of time, from 3 days to 28 days. The addition of $8 \%$ and more WMD enhanced maximum early UCS, thereby decreasing the swell potential. The UCS had maximum average values at 3, 7, 14, and 28 days when $4 \%$ SCBA was added for treatment, and a similar trend was indicated for the WMD treatment. The percentage increase in UCS of WMD treated soils is several times higher than that of SCBA treated soils.

(v) The experimental results indicated that expansion of soil is controlled effectively when 6\% SCBA and 10\% WMD were mixed with soil, separately. The swell pressure lowered with increase of WMD (up to $10 \%$ ) and SCBA (up to 12\%), respectively. In general, 4-6\% SCBA and 8-10\% WMD which are the optimum amount of treatment to reduce the PI decrease volumetric shrinkage, increase the unconfined strength, and decrease in swell potential indicating an obvious improvement.

\section{Data Availability}

The data supporting the results of this research are included within the study.

\section{Conflicts of Interest}

The authors declare that there are no conflicts of interest.

\section{Acknowledgments}

The Key Project of the National Natural Science Foundation of China (Grant no. 41630633) and Key Special Project of the Ministry of Science and Technology of People's Republic of China for Monitoring, Warning, and Prevention of Major Natural Disasters are acknowledged for the financial support.

\section{References}

[1] N. Ijaz, F. Dai, and Z. u. Rehman, "Paper and wood industry waste as a sustainable solution for environmental vulnerabilities of expansive soil: a novel approach," Journal of Environmental Management, vol. 262, Article ID 110285, 2020 b.

[2] G. Xiang, Y. Xu, F. Yu, Y. Fang, and Y. Wang, "Prediction of swelling characteristics of compacted GMZ bentonite in salt solution incorporating ion-exchange reactions," Clays and Clay Minerals, vol. 67, no. 2, pp. 163-172, 2019a.

[3] S. Aryal and P. Kolay, "Long-Term durability of ordinary portland cement and polypropylene fibre stabilized kaolin soil using wetting-drying and freezing-thawing test," International Journal of Geosynthetics and Ground Engineering, vol. 6, pp. 1-15, 2020.

[4] H. Pi, D. R. Huggins, and B. Sharratt, "Wind erosion of soil influenced by clay amendment in the inland Pacific Northwest, USA," Land Degradation \& Development, 2020.

[5] M. Singh, B. Sarkar, N. S. Bolan, Y. S. Ok, and G. J. Churchman, "Decomposition of soil organic matter as affected by clay types, pedogenic oxides and plant residue addition rates," Journal of Hazardous Materials, vol. 374, pp. 11-19, 2019.

[6] V. Yarkin and N. Lobacheva, "Stress-strain state of expansive soils when soaking from above," IOP Conference Series: Materials Science and Engineering, vol. 869, Article ID 052052, 2020.

[7] P. Zhang, J. Huang, P. Zhang et al., "Swelling suppression of black cotton soil by means of liquid immersion and surface modification," Heliyon, vol. 5, no. 12, Article ID e02999, 2019.

[8] E. Mehmood, M. Ilyas, and K. Farooq, GSP 211, 2011 b.

[9] X. Li, C. Li, and Y. Xu, "Representation of volume change for bentonite in saline solution based on modified effective stress," KSCE Journal of Civil Engineering, vol. 23, no. 5, pp. 2065-2073, 2019.

[10] L. Liu, "Prediction of swelling pressures of different types of bentonite in dilute solutions," Colloids and Surfaces A: Physicochemical and Engineering Aspects, vol. 434, pp. 303318, 2013.

[11] G. Xiang, W. Ye, F. Yu, Y. Wang, and Y. Fang, "Surface fractal dimension of bentonite affected by long-term corrosion in alkaline solution," Applied Clay Science, vol. 175, pp. 94-101, 2019b.

[12] Y. Xu, "Fractal model for the correlation relating total suction to water content of bentonites," Fractals, vol. 26, no. 3, Article ID 1850028, 2018.

[13] Y. Xu and S. Liu, "Fractal character of grain-size distribution of expansive soils," Fractals, vol. 07, no. 4, pp. 359-366, 1999.

[14] S. K. Dash and M. Hussain, "Lime stabilization of soils: reappraisal," Journal of Materials in Civil Engineering, vol. 24, pp. 707-714, 2011.

[15] X.-y Li and Y.-f Xu, "Determination and application of osmotic suction of saline solution in clay," Environmental Earth Sciences, vol. 79, pp. 1-14, 2020.

[16] E. Mehmood, M. Ilyas, and K. Farooq, "Effect of initial placement conditions on swelling characteristics of expansive soils," in Proceedings of the Geo-Frontiers 2011: Advances in Geotechnical Engineering, pp. 2397-2403, Dallas, Texas, March 2011a.

[17] A. A. Al-Rawas, A. W. Hago, and H. Al-Sarmi, "Effect of lime, cement and Sarooj (artificial pozzolan) on the swelling potential of an expansive soil from Oman," Building and Environment, vol. 40, no. 5, pp. 681-687, 2005a.

[18] R. L. Buhler and A. B. Cerato, "Stabilization of Oklahoma expansive soils using lime and Class C fly ash ASCE," Geotechnical Special Publication, vol. 162, pp. 1-10, 2007a.

[19] R. Katti, U. Kulkarni, A. Katti, and R. Kulkarni, "Stabilization of embankment on expansive soil-a case study. in: experimental and applied modeling of unsaturated soils," in Proceedings of the Sessions of GeoShanghai 2010, pp. 181-189, ASCE, Shanghai, China, June 2010.

[20] Z. Nalbantoğlu, "Effectiveness of class C fly ash as an expansive soil stabilizer," Construction and Building Materials, vol. 18, pp. 377-381, 2004.

[21] A. Seco, F. Ramírez, L. Miqueleiz, and B. García, "Stabilization of expansive soils for use in construction," Applied Clay Science, vol. 51, no. 3, pp. 348-352, 2011.

[22] D. S. Vijayan and D. Parthiban, "Effect of solid waste based stabilizing material for strengthening of expansive soil- a review," Environmental Technology \& Innovation, vol. 20, Article ID 101108, 2020.

[23] E. Ene and C. Okagbue, "Some basic geotechnical properties of expansive soil modified using pyroclastic dust," Engineering Geology, vol. 107, no. 1-2, pp. 61-65, 2009. 
[24] I. C. Christopher and N. D. Chimobi, "Emerging trends in expansive soil stabilisation: a review," Journal of Rock Mechanics and Geotechnical Engineering, vol. 11, no. 2, pp. 423-440, 2019.

[25] N. Ijaz, F. Dai, L. Meng, Z. u. Rehman, and H. Zhang, "Integrating lignosulphonate and hydrated lime for the amelioration of expansive soil: a sustainable waste solution," Journal of Cleaner Production, vol. 254, Article ID 119985, 2020a.

[26] J. James and P. K. Pandian, "Industrial wastes as auxiliary additives to cement/lime stabilization of soils," Advances in Civil Engineering, vol. 2016, Article ID 1267391, 2016.

[27] H. Hasan, H. Khabbaz, and B. Fatahi, "Expansive soil stabilization using lime-bagasse ash," in Proceedings of the GeoVancouver, Vancouver, Canada, October 2016.

[28] Z. J. Taher, J. Scalia IV, and C. A. Bareither, "Comparative assessment of expansive soil stabilization by commercially available polymers," Transportation Geotechnics, vol. 24, Article ID 100387, 2020.

[29] F. G. Bell, "Lime stabilization of clay minerals and soils," Engineering Geology, vol. 42, no. 4, pp. 223-237, 1996.

[30] A. A. Al-Rawas, A. W. Hago, and H. Al-Sarmi, "Effect of lime, cement and Sarooj (artificial pozzolan) on the swelling potential of an expansive soil from Oman," Building and Environment, vol. 40, no. 5, pp. 681-687, 2005b.

[31] J. B. Croft, "The influence of soil mineralogical composition on cement stabilization," Géotechnique, vol. 17, no. 2, pp. 119-135, 1967.

[32] L. K. Sharma, N. N. Sirdesai, K. M. Sharma, and T. N. Singh, "Experimental study to examine the independent roles of lime and cement on the stabilization of a mountain soil: a comparative study," Applied Clay Science, vol. 152, pp. 183-195, 2018.

[33] R. L. Buhler and A. B. Cerato, "Stabilization of Oklahoma expansive soils using lime and class $\mathrm{C}$ fly ash. In: problematic Soils and Rocks and in Situ Characterization," in Proceedings of the Geo-Denver, pp. 1-10, Denver, Colorado, February 2007b.

[34] P. Dahale, P. Nagarnaik, and A. Gajbhiye, "Effect of flyash and lime on stabilization of expansive soil," i-Manager's Journal on Civil Engineering, vol. 6, p. 8, 2016.

[35] B. R. Phani Kumar and R. S. Sharma, "Effect of fly ash on engineering properties of expansive soils," Journal of Geotechnical and Geoenvironmental Engineering, vol. 130, no. 7, pp. 764-767, 2004.

[36] A. Puppala, L. Hoyos, C. Viyanant, and C. Musenda, "Fiber and fly ash stabilization methods to treat soft expansive soils," Soft Ground Technology, pp. 136-145, 2001 a.

[37] M. Alhassan, "Potentials of rice husk ash for soil stabilization," Assumption university journal of technology, vol. 11, pp. 246-250, 2008.

[38] A. Kumar and D. Gupta, "Behavior of cement-stabilized fiber-reinforced pond ash, rice husk ash-soil mixtures," Geotextiles and Geomembranes, vol. 44, no. 3, pp. 466-474, 2016.

[39] Y. Liu, C.-W. Chang, A. Namdar et al., "Stabilization of expansive soil using cementing material from rice husk ash and calcium carbide residue," Construction and Building Materials, vol. 221, pp. 1-11, 2019.

[40] B. R. Phanikumar and T. V. Nagaraju, "Effect of fly ash and rice husk ash on index and engineering properties of expansive clays," Geotechnical \& Geological Engineering, vol. 36, no. 6, pp. 3425-3436, 2018.
[41] A. F. Cabalar, D. I. Hassan, and M. D. Abdulnafaa, "Use of waste ceramic tiles for road pavement subgrade," Road Materials and Pavement Design, vol. 18, no. 4, pp. 882-896, 2017.

[42] C. Medina, M. Frías, and M. I. Sánchez de Rojas, "Microstructure and properties of recycled concretes using ceramic sanitary ware industry waste as coarse aggregate," Construction and Building Materials, vol. 31, pp. 112-118, 2012.

[43] L. A. Pereira-de-Oliveira, J. P. Castro-Gomes, and P. M. S. Santos, "The potential pozzolanic activity of glass and red-clay ceramic waste as cement mortars components," Construction and Building Materials, vol. 31, pp. 197-203, 2012.

[44] V. R. Babu and C. A. Kasetty, "Study on strength properties of expansive soil treated with lime and nano silica," International Journal of Science and Research, vol. 6, no. 10, pp. 64-67, 2017.

[45] A. Mostafa, M. S. Ouf, and M. Elgendy, "Stabilization of subgrade pavement layer using silica fume and nano silica," International Journal of Scientific Engineering and Research, vol. 7, pp. 573-581, 2016.

[46] J. Nelson and D. J. Miller, Expansive Soils: Problems and Practice in Foundation and Pavement Engineering, John Wiley \& Sons, Hoboken, New Jersey, 1997.

[47] M. A. Pashabavandpouri and S. Jahangiri, "Effect of nano silica on swelling, compaction and strength properties of clayey soil stabilized with lime," J Appl Environ Biol Sci, vol. 5, pp. 538-548, 2015.

[48] S. S. Shahin, L. A. E.-M. Fayed, and E. H. Ahmad, "Review of nano additives in stabilization of soil," Seventh International Conference on Nano Technology in Construction, vol. 1, no. 1, 2015.

[49] N.-J. Jiang, Y.-J. Du, S.-Y. Liu, M.-L. Wei, S. Horpibulsuk, and A. Arulrajah, "Multi-scale laboratory evaluation of the physical, mechanical, and microstructural properties of soft highway subgrade soil stabilized with calcium carbide residue," Canadian Geotechnical Journal, vol. 53, pp. 373-383, 2015.

[50] A. Kampala and S. Horpibulsuk, "Engineering properties of silty clay stabilized with calcium carbide residue," Journal of Materials in Civil Engineering, vol. 25, pp. 632-644, 2012.

[51] N. Latifi, F. Vahedifard, E. Ghazanfari, and A. S. Rashid, "Sustainable usage of calcium carbide residue for stabilization of clays," Journal of Materials in Civil Engineering, vol. 30, no. 6, Article ID 04018099, 2018.

[52] M. Gueddouda, I. Goual, M. Lamara, A. Smaida, and B. Mekarta, "Chemical stabilization of expansive clays from Algeria," Global Journal of Researches in Engineering, vol. 11, pp. 1-7, 2011.

[53] S. He, "Chemical stabilization of expansive soils using liquid ionic soil stabilizers (LISS)," 2019.

[54] H. A. Ismaiel and M. M. Badry, "Lime chemical stabilization of expansive deposits exposed at El-Kawther Quarter," Sohag region, Egypt Geosciences, vol. 3, pp. 89-98, 2013.

[55] E. Mutaz, M. A. Shamrani, A. J. Puppala, and M. A. Dafalla, "Evaluation of chemical stabilization of a highly expansive clayey soil," Transportation Research Record: Journal of the Transportation Research Board, vol. 2204, no. 1, pp. 148-157, 2011.

[56] A. J. Puppala and A. Pedarla, "Innovative ground improvement techniques for expansive soils," Innovative Infrastructure Solutions, vol. 2, no. 1, p. 24, 2017.

[57] M. H. Al-Malack, G. M. Abdullah, O. S. B. Al-Amoudi, and A. A. Bukhari, "Stabilization of indigenous Saudi Arabian 
soils using fuel oil flyash," Journal of King Saud University Engineering Sciences, vol. 28, no. 2, pp. 165-173, 2016.

[58] R. Brooks, F. F. Udoeyo, and K. V. Takkalapelli, "Geotechnical properties of problem soils stabilized with fly ash and limestone dust in Philadelphia," Journal of Materials in Civil Engineering, vol. 23, pp. 711-716, 2010.

[59] T. M. Petry and D. N. Little, "Review of stabilization of clays and expansive soils in pavements and lightly loaded structures-history, practice, and future," Journal of Materials in Civil Engineering, vol. 14, 2002.

[60] J. K. Mitchell and K. Soga, Fundamentals of Soil Behavior, Vol. 3, John Wiley \& Sons, New York, 2005.

[61] A. Puppala, L. Hoyos, C. Viyanant, and C. Musenda, GSP $112,2001 b$.

[62] B. M. Devi and H. S. Chore, "Feasibility study on bagasse ash as light weight material for road construction," Materials Today: Proceedings, vol. 27, 2020.

[63] W. Dong, Y. Lu, W. Wang, M. Zhang, Y. Jing, and A. Wang, "A sustainable approach to fabricate new $1 \mathrm{D}$ and $2 \mathrm{D}$ nanomaterials from natural abundant palygorskite clay for antibacterial and adsorption," Chemical Engineering Journal, vol. 382, Article ID 122984, 2020.

[64] H. Hasan, L. Dang, H. Khabbaz, B. Fatahi, and S. Terzaghi, "Remediation of expansive soils using agricultural waste bagasse ash," Procedia engineering, vol. 143, pp. 1368-1375, $2016 \mathrm{a}$.

[65] J. T. Hatmoko and H. Suryadharma, "Shear behavior of calcium carbide residue - bagasse ash stabilized expansive soil," Procedia Engineering, vol. 171, pp. 476-483, 2017.

[66] S. Mulay, G. Vesmawala, Y. Patil, and V. Gholap, "Experimental investigation of sugarcane bagasse ash concrete under sodium hydroxide solution," American Journal of Civil Engineering, vol. 5, no. 1, pp. 1-8, 2017.

[67] C. Gupta and R. K. Sharma, "Influence of marble dust, fly ash and beas sand on sub grade characteristics of expansive soil," Journal of Mechanical and Civil Engineering, pp. 13-18, 2014.

[68] A. K. Jain and A. K. Jha, "Geotechnical behaviour and microanalyses of expansive soil amended with marble dust," Soils and Foundations, vol. 60, pp. 737-751, 2020.

[69] C. O. Okagbue and T. U. S. Onyeobi, "Potential of marble dust to stabilise red tropical soils for road construction," Engineering Geology, vol. 53, no. 3-4, pp. 371-380, 1999.

[70] S. Hussain, "Effect of compaction energy on engineering properties of expansive soil," Civil Engineering Journal, vol. 3, no. 8, pp. 610-616, 2017.

[71] J. Israr, K. Farooq, and H. Mujtaba, "Modelling of swelling parameters and associated characteristics based on index properties of expansive soils," Pakistan Journal of Engineering and Applied Sciences, 2016.

[72] F. E. Jalal, Y. Xu, B. Jamhiri, and S. A. Memon, "On the recent trends in expansive soil stabilization using calcium-based stabilizer materials (csms): a comprehensive review," Advances in Materials Science and Engineering, vol. 2020, pp. 1-23, 2020.

[73] H. Mujtaba, T. Aziz, K. Farooq, N. Sivakugan, and B. M. Das, "Improvement in engineering properties of expansive soils using ground granulated blast furnace slag," Journal of the Geological Society of India, vol. 92, no. 3, pp. 357-362, 2018.

[74] J. Mumtaz, I. Rashid, and J. Israr, "Laboratory modelling of strength and deformation characteristics of a high swelling soil treated with industrial wastes," Arabian Journal of Geosciences, vol. 13, pp. 1-12, 2020.

[75] A. Naseem, W. Mumtaz, H. Fazal-e-Jalal, and H. De Backer, "Stabilization of expansive soil using tire rubber powder and cement kiln dust," Soil Mechanics and Foundation Engineering, vol. 56, no. 1, pp. 54-58, 2019.

[76] L. Xu, F. Zha, C. Liu, B. Kang, J. Liu, and C. Yu, "Experimental investigation on carbonation behavior in lime-stabilized expansive soil," Advances in Civil Engineering, vol. 2020, Article ID 7865469, 2020.

[77] H. MolaAbasi, S. Naderi Semsani, M. Saberian, A. Khajeh, J. Li, and M. Harandi, "Evaluation of the long-term performance of stabilized sandy soil using binary mixtures: a micro- and macro-level approach," Journal of Cleaner Production, vol. 267, Article ID 122209, 2020.

[78] J. Pooni, D. Robert, F. Giustozzi, S. Setunge, and S. Venkatesan, "Stabilisation of expansive soils subjected to moisture fluctuations in unsealed road pavements," International Journal of Pavement Engineering, vol. 2020, Article ID 1762083, 13 pages, 2020.

[79] M. A. Mu'Azu, "Influence of compactive effort on Bagasse ash with cement treated lateritic soil," Leonardo Electronic Journal of Practices and Technologies, vol. 10, pp. 79-92, 2007.

[80] K. J. Osinubi, T. S. Ijimdiya, and I. Nmadu, "Lime stabilization of black cotton soil using bagasse ash as admixture," Advanced Materials Research, vol. 62-64, pp. 3-10, 2009.

[81] A. S. Kharade, V. V. Suryavanshi, B. S. Gujar, and R. R. Deshmukh, "Waste product bagasse ash from sugar industry can be used as stabilizing material for expansive soils," International Journal of Renewable Energy Technology, vol. 3, pp. 506-512, 2014.

[82] R. Ditta, V. Singh, and T. Sabo, "The effect of waste marble dust in stabilization of expansive soil,".

[83] G. Tamiru and P. Ponnurangam, "Effect of marble dust for stabilization of expansive soil," CIKITUSI Journal for Multidisciplinary Research, vol. 6, no. 1, pp. 46-56, 2019.

[84] S. A. Aiban, "Compressibility and swelling characteristics of Al-Khobar Palygorskite, eastern Saudi Arabia," Engineering Geology, vol. 87, no. 3-4, pp. 205-219, 2006.

[85] A. Marsh, A. Heath, P. Patureau, P. Evernden, and P. Walker, "Influence of clay minerals and associated minerals in alkali activation of soils," Construction and Building Materials, vol. 229, Article ID 116816, 2019.

[86] M. Syed, A. GuhaRay, S. Agarwal, and A. Kar, "Stabilization of expansive clays by combined effects of geopolymerization and fiber reinforcement," Journal of the Institution of Engineers: Series A, vol. 101, no. 1, pp. 163-178, 2020.

[87] J. Cui, Z. Zhang, and F. Han, "Effects of $\mathrm{pH}$ on the gel properties of montmorillonite, palygorskite and montmorillonite-palygorskite composite clay," Applied Clay Science, vol. 190, Article ID 105543, 2020.

[88] S. Mazhar and A. GuhaRay, "Stabilization of expansive clay by fibre-reinforced alkali-activated binder: an experimental investigation and prediction modelling," International Journal of Geotechnical Engineering, vol. 2020, Article ID 1775358, 17 pages, 2020.

[89] P. Jamsawang, H. Poorahong, N. Yoobanpot, S. Songpiriyakij, and H. Jongpradist, "Improvement of soft clay with cement and bagasse ash waste," Construction and Building Materials, vol. 154, pp. 61-71, 2017.

[90] C. Gupta, R. K. Sharma, and R. K. Sharma, "Black cotton soil modification by the application of waste materials," Periodica Polytechnica Civil Engineering, vol. 60, no. 4, pp. 479-490, 2016.

[91] Ş. Öncü and H. Bilsel, "Utilization of waste marble to enhance volume change and strength characteristics of sandstabilized expansive soil," Environmental earth sciences, vol. 77, no. 12, p. 461, 2018. 
[92] R. Alavéz-Ramírez, P. Montes-García, J. Martínez-Reyes, D. C. Altamirano-Juárez, and Y. Gochi-Ponce, "The use of sugarcane bagasse ash and lime to improve the durability and mechanical properties of compacted soil blocks," Construction and Building Materials, vol. 34, pp. 296-305, 2012.

[93] E. A. Basha, R. Hashim, H. B. Mahmud, and A. S. Muntohar, "Stabilization of residual soil with rice husk ash and cement," Construction and Building Materials, vol. 19, no. 6, pp. 448-453, 2005.

[94] R. S. Abdulla and N. Majeed, "Some physical properties treatment of expansive soil using marble waste powder," International Journal of Engineering Research and Technology, vol. 3, pp. 591-600, 2014.

[95] Akinwumi II and C. A. Booth, "Experimental insights of using waste marble fines to modify the geotechnical properties of a lateritic soil," Journal of Environmental Engineering and Landscape Management, vol. 23, no. 2, pp. 121-128, 2015.

[96] L. Ali and Z. Zafar, "Construction on expansive soils in semi arid zone," in Instrumentation, Testing, and Modeling of Soil and Rock Behavior, pp. 256-263, ASCE, Hunan, China, 2011.

[97] M. Dayioglu, B. Cetin, and S. Nam, "Stabilization of expansive Belle Fourche shale clay with different chemical additives," Applied Clay Science, vol. 146, pp. 56-69, 2017.

[98] G. Radhakrishnan, M. A. Kumar, and G. Raju, "Swelling properties of expansive soils treated with chemicals and fly ash," Am J Eng Res, vol. 3, pp. 245-250, 2014.

[99] A. K. Sabat, "Utilization of bagasse ash and lime sludge for construction of flexible pavements in expansive soil areas Electronic," Journal of Geotechnical Engineering, vol. 17, pp. 1037-1046, 2012.

[100] F. G. Bell, Engineering Treatment of Soils, CRC Press, Boca Raton, Florida, 2014.

[101] S. Im, "Sensitivity estimates for nonlinear mathematical models," Mathematical Modelling in Civil Engineering, vol. 1, pp. 407-414, 1993.

[102] S. Mazhar, A. GuhaRay, A. Kar, G. S. S. Avinash, and R. Sirupa, "Stabilization of expansive black cotton soils with alkali activated binders," Springer Series in Geomechanics and Geoengineering, Springer, in Proceedings of the ChinaEurope Conference on Geotechnical Engineering, pp. 826-829, August 2018. 